\title{
Molekulargenetische Diagnostik - Was wissen die Maschinen? Was wollen wir wissen?
}

\author{
Peter Bauer ${ }^{a} \quad$ Michael Hummel $^{b}$ Christof von Kalle ${ }^{c}$ Rita Schmutzler ${ }^{d} \quad$ Andreas Block $^{e}$ \\ Matthias Stroth ${ }^{f}$ Christiane Woopen $^{g}$ Karsten Engelke ${ }^{h}$
}

a Institut für Medizinische Genetik und Angewandte Genomik, Tübingen und Centogene AG, Rostock, Deutschland;

${ }^{b}$ Institut für Pathologie, Charité - Universitätsmedizin Berlin, Berlin, Deutschland;

${ }^{\mathrm{c}}$ Translationale Onkologie, Deutsches Krebsforschungszentrum, Heidelberg, Deutschland;

${ }^{d}$ Zentrum für familiären Brust- und Eierstockkrebs, Frauenklinik, Universitätsklinikum Köln, Deutschland;

eII. Medizinische Klinik und Poliklinik, Universitäres Cancer Center Hamburg UCCH, Universitätsklinikum Hamburg-Eppendorf, Hamburg, Deutschland;

${ }^{f}$ Maria Heimsuchung Caritas-Klinik Pankow, Berlin, Deutschland;

gForschungsstelle Ethik, Universitätsklinikum Köln, und CERES, Universität zu Köln, Köln, Deutschland;

${ }^{\mathrm{h}}$ Dierks+Bohle Rechtsanwälte Partnerschaft mbB, Berlin, Deutschland

\begin{abstract}
Status der molekulargenetischen Diagnostik Stellenwert der molekularen Diagnostik aus Sicht des Humangenetikers
\end{abstract}

\section{Referent: Peter Bauer, Tübingen/Rostock}

Die molekulargenetische Diagnostik mit Hilfe der Gensequenzierung hat innerhalb kurzer Zeit enorme Fortschritte gemacht. Brauchte es zu Zeiten des Humangenomprojekts noch mehrere Jahre, um ein einzelnes Genom zu entschlüsseln, so können heute Genome innerhalb von nur $36 \mathrm{~h}$ vollständig sequenziert werden. Mit neuen Techniken werden jährlich tausende Genome bzw. Exome hinsichtlich ihrer Erbinformationen analysiert.

Für das moderne Next Generation Sequencing (NGS) als Weiterentwicklung der klassischen Sanger-Sequenzierung wurde eine Reihe von Geräten entwickelt, die teilweise bereits wieder von noch effizienter arbeitenden Geräten abgelöst worden sind. Ausgangsmaterial für das NGS ist die DNA aus einer Gewebe- oder Tumorprobe. Sie wird in kleine Schnipsel fragmentiert, wobei je nach Fragestellung ausgewählte Abschnitte angereichert werden können. Die Sequenzierung des kompletten Genoms erfordert stets eine Amplifizierung zur Vervielfältigung der Nukleinsäuren [1]. Sie erfolgt auf einer miniaturisierten Plattform mittels PCR beispielsweise in Form einer Cluster-Amplifizierung. Dadurch wird das Ausgangsmaterial modifiziert und für die Sequenzierung aufbereitet. Diese Cluster werden milliardenfach parallel sequenziert und als hochauflösende Einzelbilder, pro sequenzierter Base, abgespeichert. Die Bioinformatik verarbeitet dann diese großen Mengen an
Bildinformationen und liefert schließlich die abgefragte Sequenzinformation mit den zugehörigen Sequenzvarianten. Durch Automatisierung der einzelnen Prozessabläufe (Abb. 1) ist die Sequenzierung in den vergangenen Jahren deutlich kostengünstiger geworden. Dieser Trend dürfte sich weiter fortsetzen, insbesondere wenn künftig auf eine Amplifikation verzichtet werden kann. Kosten von etwa 100,- USD pro Genom-Sequenzierung rücken dann in greifbare Nähe. Technisch werden bei diesem Verfahren einzelne Moleküle aus einer Tumor- oder Blutzelle mit einem Polymerase-Enzym in einer sogenannten Nanopore sequenziert. Die Sequenzierung auf Ebene eines Einzelmoleküls (single molecule sequencing) ist zwar technisch noch nicht ausgereift, die dafür nötigen Mikrochips sind aber in fortgeschrittener Entwicklung. Die Prototypen dieser Geräte haben noch keine diagnostische Qualität, doch diese dürfte bald erreicht werden.

An molekulargenetische Tests werden hohe Anforderungen gestellt. Primär geht es darum, die relevanten Mutationen in dem zu untersuchenden Gen möglichst vollständig zu erfassen. Ebenso sollten Dosisveränderungen des Genoms - verursacht etwa durch fehlende oder duplizierte Genabschnitte - zuverlässig erkannt werden. Idealerweise werden epigenetische Veränderungen miterfasst, weil diese bei einer Reihe von Erbkrankheiten eine große Rolle spielen. Diese Auflagen werden von modernen Sequenziermaschinen noch nicht vollständig erfüllt. Der Illumina Genome Analyzer z.B. extrahiert nahezu alle Einzelbasenvarianten und liefert relativ zuverlässige Gendosisanalysen, kann aber nicht standardmäßig epigenetische Veränderungen messen, und auch niederfrequente Mosaike lassen sich nur mit hohem finanziellen Aufwand abbilden. 


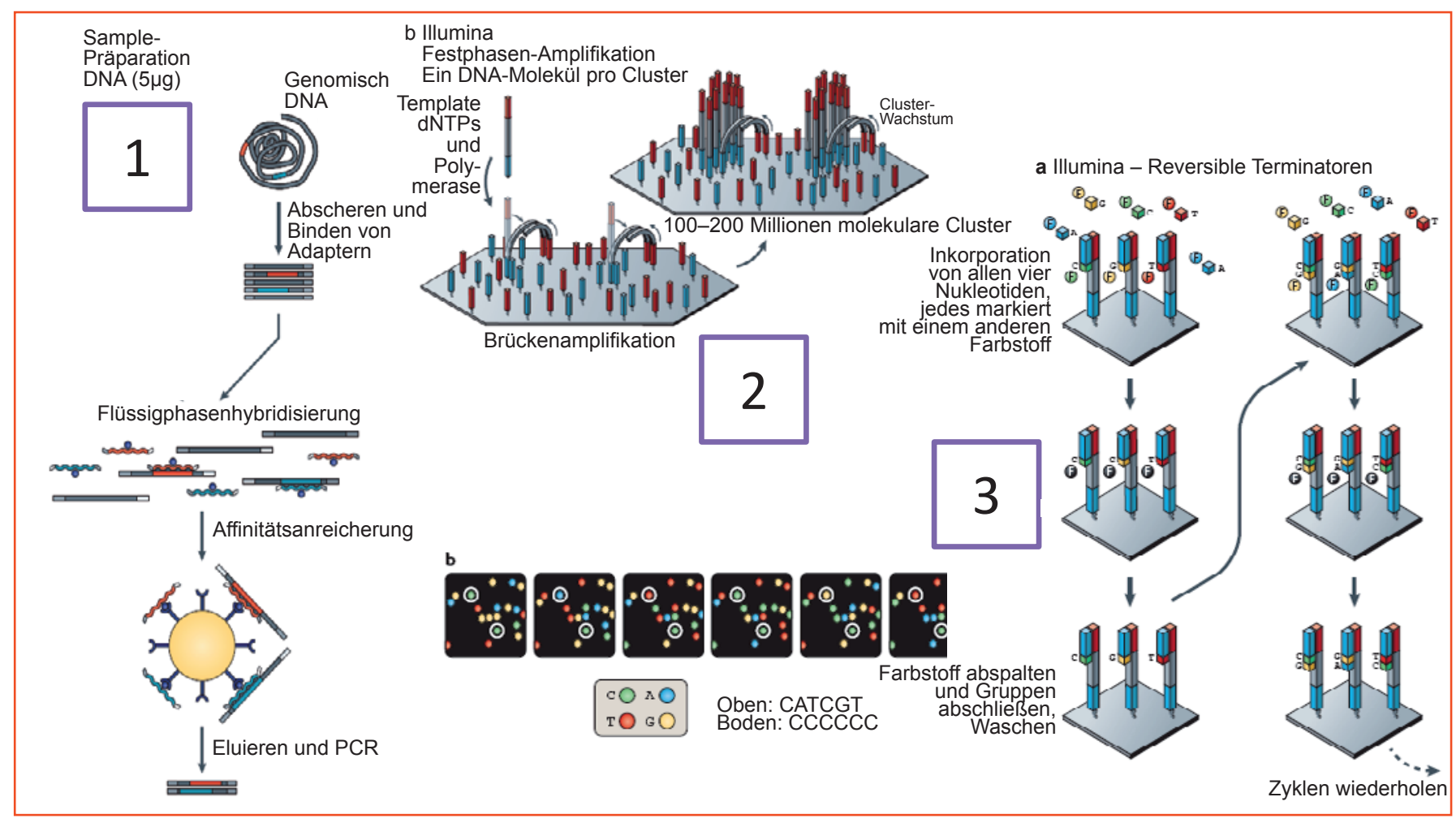

Abb. 1. Arbeitsprozesse bei der NGS-Sequenzierung (modifiziert nach [1]).

Tab. 1. Sensitivität molekulargenetischer Tests

\begin{tabular}{llccc}
\hline & Gene & Tiefe & Lesevorgänge & Abdeckung \\
\hline Gesamt-Genom-Sequenzierung & 20000 & $30 \times$ & $500 \mathrm{M}$ & $97 \%>10 \times$ \\
Gesamt-Exom-Sequenzierung & 20000 & $100 \times$ & $50 \mathrm{M}$ & $90 \%>20 \times$ \\
Clinical Exome Sequencing & 5000 & $250 \times$ & $10 \mathrm{M}$ & $95 \%>20 \times$ \\
Gene Panel Sequencing & $50-2000$ & $400 \times$ & $2 \mathrm{M}$ & $97 \%>20 \times$ \\
\hline
\end{tabular}

Die Sensitivität der eingesetzten Technologien, insbesondere die des NGS, hängt davon ab, ob in dem für die Analyse aufbereiteten Genom ausreichend Ableseinformationen («sequence reads») für das vermutete mutationsauffällige Gen produziert wurden und wie gut die verschiedenen Analyzer diese Informationen verarbeiten können. Wird das gesamte Genom sequenziert, werden neben etwa 20000 Genen auch alle nichtkodierenden Sequenzinformationen produziert; üblicherweise werden pro Base etwa 30 voneinander unabhängige Beobachtungen hergestellt (vertikale Sequenziertiefe; Tab. 1), dies allerdings nur mit einer Abdeckung von etwa 97\% der untersuchten Bereiche. Mit eine solchen Tiefe ist eine Mosaikmessung nicht möglich, weil die Zahl der abweichenden «Reads» in der Probe in der Regel zu gering ist. Die Exom-Sequenzierung hat ein vergleichbares Sequenzierpotential, besitzt jedoch eine größere Tiefe (etwa 100 Sequenzen/Base). Sie eignet sich deshalb besser für Mosaike, deckt aber nur etwa $90 \%$ der analysierten Regionen ab. Vollständigere Ergebnisse liefert die Analyse einzelner krankheitsrelevanter Gene (Clinical Exome Sequencing). Durch die Konzentration der Sequenzierung auf bestimmte Gene erhöht sich die vertikale Tiefe. Die höchste Abdeckung hat das Gene Panel Sequencing, das sich auf wenige krankheitsrelevante
Gene (BRCA, Ovarialkarzinom-Panel) beschränkt und eine Sensitivität von nahezu $100 \%$ besitzt. Dabei ist mit Sensitivität eine technische Messgröße (Abdeckungsrate) gemeint, die nicht mit der klinischen Sensitivität identisch ist. Befindet sich eine Mutation in einem durch das gewählte Verfahren nicht abgedeckten Bereich, ist die klinische Sensitivität $0 \%$. Um eine hohe klinische Sensitivität zu erreichen, sollte die Fragestellung möglichst eng definiert sein. Am Beispiel einer Kardiomyopathie lässt sich aufzeigen, dass sich durch Begrenzung auf die krankheitsrelevanten Gene bzw. eine noch engere Beschränkung auf solche Gene, die für die phänotypische Ausprägung des Krankheitsbilds codieren, eine hohe technische und klinische Sensitivität durch Wahl des optimalen Tests erreichen lässt [2]. Dies gilt sowohl für den Nachweis von Keimbahnmutationen als auch für somatische Mutationen.

Bei der Sequenzierung fällt eine Fülle von Datenmaterial an, darunter auch zahlreiche Informationen, die über den nachgefragten Diagnosebefund hinausgehen und bei denen zu klären ist, ob und an wen diese Informationen weiterzugeben sind. Hinzu kommen mögliche falsch-positive Befunde: Sie können laborgeneriert sein, etwa durch Amplifikations- oder Mapping-Artefakte, oder es können Zufallsbefunde sein, wie sie bei der Aufbereitung 
Tab. 2. Durchschnittliche Single-Nucleotid-Varianten (SNV) - Konkordanz über 15 Exome zwischen fünf verschiedenen Variant-calling-Pipelines (modifiziert nach [3])

\begin{tabular}{llll}
\hline Mapping tool & GATK & SAMTools & SOAPindel \\
\hline GATK & $28,5 \%$ & $7,1 \%$ & $6,8 \%$ \\
SAMTools & $26,8 \%$ & $7,8 \%$ & $0,5 \%$ \\
SOAPindel & & & $22,4 \%$ \\
\hline
\end{tabular}

eines kompletten Genoms anstelle ausgewählter Gene leicht anfallen können. Eine diagnostische Herausforderung sind auch Sequenzvarianten, die selten sind und deshalb schwer zu klassifizieren. Die Interpretation bezüglich der Pathogenität solcher Raritäten kann Probleme bereiten. Auch die Bioinformatik hat mit technischen Einschränkungen zu kämpfen [3], zumal es teilweise zu geringe Überschneidungen bei den verwendeten Software-Tools gibt (Tab. 2). Diesen Problemen kann nur durch Optimierung auf der Sequenzierebene begegnet werden.

Anders als anfänglich befürchtet, hält sich die Zahl der für klar krankheitsassoziierte Anomalien codierenden Gene in überschaubaren Grenzen. Es gibt meist nur einzelne erklärende Mutationen für den Phänotyp sowie eine Handvoll Varianten [4], so dass die möglichen Befunde dem Patienten im Rahmen des gendiagnostischen Aufklärungsgesprächs gut vermittelt werden können.

Bei etwa 5-10\% der Patienten führt die humangenetische Untersuchung zu mehr als einer Diagnose [4], etwa das Zusammentreffen einer erblichen Muskelerkrankung und einer Epilepsie mit einer sich überlagernden phänotypischen Ausprägung. Beide Krankheiten lassen sich durch die Mutationsanalysen klar voneinander abgrenzen, was vor wenigen Jahren noch nicht möglich war.

Die Interpretation der gefundenen Mutationsvarianten hinsichtlich ihrer Pathogenität bereitet nach wie vor Schwierigkeiten [5]. Bis zu 20\% der in öffentlich zugänglichen Mutationsdatenbanken beschriebenen Pathogenitätszuordnungen sind vermutlich falsch. Hilfreich sind die Klassifizierung von Pathogenitätsmerkmalen nach einem definierten Schema und die Archivierung der Befunde in zuverlässigen Datenbanken. Die von dem Unternehmen CENTOGENE betriebene Mutationsdatenbank CentoMD ${ }^{\circledR}$ fokussiert auf seltene Krankheiten und nimmt ausschließlich molekulare Diagnosen aus zertifizierten Laboren mit dem zugehörigen Phänotypus über eine Terminologie (Human Phenotype Ontology; HPO) auf. Darin sind auch die Kriterien vermerkt, die zur Klassifizierung der Mutation geführt haben. Die Datenbank erlaubt Genotyp-Phänotyp-Korrelationen und erfüllt die Qualitätsanforderungen für die Zertifizierung als Medizinprodukt. Sie wird ständig aktualisiert, auch bezüglich einer möglichen NeuKlassifizierung bekannter Mutationen, und kann deshalb auch zur Überprüfung bereits früher gestellter Diagnosen dienen. Bei allen Fortschritten muss sich die humangenetische Diagnostik dabei strikt an Qualitätsauflagen halten, wie sie in diagnostischen Leitlinien definiert sind [6].

Ein immer größer werdender Bereich der Humangenetik befasst sich mit Fragen zur Prävention von Krebserkrankungen durch frühzeitige Erkennung genetischer Risiken. Denkbar wären nationale Screening-Programme etwa zur Abschätzung des Ovarialkarzinom-Risikos durch BRCA-Mutationstestung. Dies vor dem Hintergrund, dass etwa $20 \%$ der Frauen mit Ovarialkarzinom eine BRCA1/2-Keimbahn-Mutation haben [7]. Insbesondere die Möglichkeit der Therapie mit PARP-Inhibitoren bei Mutationsnachweis lassen die genetische Testung womöglich aller Frauen sinnvoll erscheinen. Der hohe Stellenwert der Molekulardiagnostik zum Nachweis von Treibermutationen im BRAF-Gen ist bekannt, zumal sich daraus ebenfalls effektive Therapiekonzepte ableiten lassen $[8,9]$. Mit der Liquid Biopsy hat sich die molekulare Diagnostik und Verlaufskontrolle weiter vereinfacht [10]. Sie kann in größerem Umfang und - zumindest bei Nutzung von Gen-Panels - auch zu akzeptablen Preisen angeboten werden. Weitere Fortschritte in der Genom-Sequenzierung werden dazu beitragen, die Rolle von somatischen nichtkodierenden Sequenzen aufzudecken [11].

Mit einem Beschluss des Bewertungsausschusses zur Änderung des Einheitlichen Bewertungsmaßstabes (EBM) [12] ist das NGS bis zu einem gewissen Umfang (25kb cDNA, das entspricht etwa fünf großen Genen) abrechenbar, darüber hinaus nur auf Einzelantrag. Die somatische Genetik wird ebenfalls erstattet, nicht aber Analysen aus Liquid Biopsy. Die Sanger-Sequenzierung wird erneut um $50-80 \%$ abgewertet. Sehr bedenklich ist, dass die initiale molekulare Diagnostik «abschließend» ist und somit keine Stufendiagnostik ermöglicht. Damit dürfte sich in unklaren Fällen die Stellung einer sicheren Diagnose erheblich verzögern.

\section{Status der molekulargenetischen Diagnostik - Stellenwert der molekularen Diagnostik aus Sicht der Pathologie}

\section{Referent: Michael Hummel, Berlin}

Die molekulargenetische und die molekularpathologische Diagnostik sowie weitere Spezialbereiche lassen sich unter dem Begriff «molekulare Diagnostik» zusammenfassen, zumal die Methoden fachgebietsübergreifend eingesetzt werden. Es geht um gemeinsame Technologien zum Wohle der Patienten. Die qualitativen Voraussetzungen, zu validen Ergebnissen in der molekularpathologischen Diagnostik zu kommen [13], wurden im Rahmen von Ringversuchen geschaffen.

In der Charité Berlin wurden neue Techniken und Methoden schon immer frühzeitig in die Diagnostik integriert, beginnend mit Klonalitätsanalysen für B- und T-Zellen, den PCR-Untersuchungen und Sequenzierungen bei hämatologischen Tumoren. Heute sind wir sehr viel breiter aufgestellt - neben den immer noch aktuellen (wenn auch technisch erheblich weiterentwickelten) Klonalitätsanalysen kommt dem Nachweis somatischer Mutationen und der FISH-Analytik zum Nachweis genomischer Alterationen im Tumorgewebe solider Tumoren eine erhebliche Bedeutung zu. Doch nicht nur die DNA ist für die molekulare Diagnostik von Bedeutung, sondern auch die RNA. Genexpressionsmuster von Tumoren werden insbesondere bei Tumoren 


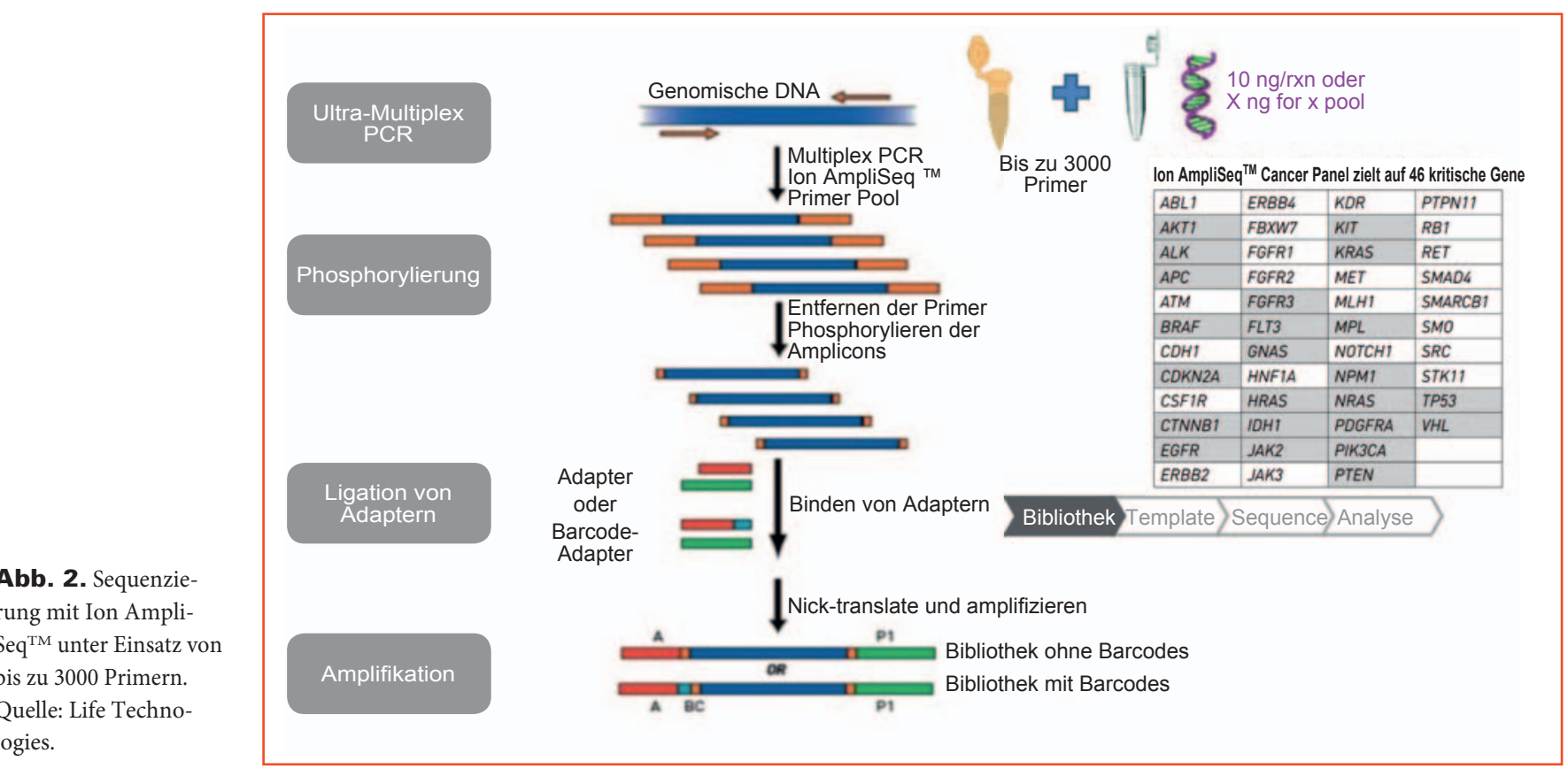

ohne bekannten Primärtumor (CUP-Syndrom) und zur Therapieplanung beim Mammakarzinom (EndoPredict ${ }^{\circledR}$ ) genutzt.

Durch die Personalisierung der Krebstherapie auf Grundlage molekulardiagnostischer Befunde hat sich die Prognose verschiedener Krebserkrankungen deutlich gebessert. Dies gilt etwa für Patienten mit nichtkleinzelligem Bronchialkarzinom (NSCLC), die bei Nachweis einer EGFR-Mutation im Tumorgewebe von Tyrosinkinase-Inhibitoren (TKI) wie z.B. Erlotinib profitieren. Wir kennen Patienten mit metastasiertem NSCLC, die zunächst mit Erlotinib und nachfolgend - durch Nachweis einer EGFR-T790M-Mutation im Lymphknotengewebe - mit dem neuesten TKI Osimertinib (Tagrisso ${ }^{\circledR}$ ) behandelt wurden. Diese Patienten waren zum Berichtszeitpunkt seit mehr als 3 Jahren in Therapie, was angesichts der initial ungünstigen Prognose als großer Therapieerfolg zu werten ist.

In der Molekulardiagnostik geht es heute darum, möglichst zeitgleich nach verschiedenen Alterationen zu fahnden, um daraus zeitnah ein Therapiekonzept zu entwickeln, das die molekularen Veränderungen des jeweiligen Patienten individuell berücksichtigt. Dafür müssen breite molekulare Analysen vorgenommen werden unter Einsatz von Assays mit hoher Sensitivität und Zuverlässigkeit. Der Zeitaufwand für diese Analysen ist kurz bemessen, da insbesondere bei aggressiv verlaufenden Krebserkrankungen sehr zeitnah mit der Therapie begonnen werden muss.

Seit Beginn der DNA-Sequenzierung nach Sanger [14] hat sich die Molekulardiagnostik kontinuierlich weiterentwickelt und ist schneller und effizienter geworden. Die Sanger-Sequenzierung ist als einfaches und robustes System immer noch weit verbreitet und detektiert zuverlässig alle Alterationen in einer amplifizierten Gensequenz. Allerdings ist beim Nachweis von Tumormutationen ein Anteil von mindestens 20-30\% Tumorzellen im Untersuchungsgut Voraussetzung. Ist eine höhere Sensitivität erforderlich - etwa wenn nur wenige Tumorzellen als Untersuchungsmaterial zur Verfügung stehen - und insbesondere wenn mehrere Sequenzabschnitte parallel analysiert werden müssen, ist die NGSTechnologie mit ihrem hohen Durchsatz vorzuziehen. Neben einer hohen Sequenzierkapazität ermöglicht NGS die Darstellung einzelner Moleküle, was eine Quantifizierung der jeweiligen Sequenzabweichung (Mutation) zulässt. Schließlich können bei Verwendung molekularer Sequenz-Barcodes mehrere Proben gleichzeitig sequenziert werden.

Die NGS hat sich mittlerweile zu einer verlässlichen Alternative zur klassischen Sanger-Sequenzierung entwickelt. In vielen pathologischen Instituten wird die NGS bereits für die Sequenzierung verschiedener definierter Genabschnitte aus fixiertem Tumormaterial verwendet (Abb. 2), wobei sich die Technik prinzipiell auch zur Untersuchung ganzer Gene oder des Exoms (sämtliche Protein kodierenden DNA-Abschnitte) eignet. Mit modernen NGS-Geräten können bis zu mehrere hundert Abschnitte eines Genoms parallel mittels Multiplex-PCR amplifiziert, nachfolgend durch den Sequenzer analysiert und die Bioinformatik in kürzester Zeit ausgewertet werden.

Diese Amplikon-basierte NGS liefert für amplifizierte Bereiche durch die Herstellung zahlreicher individueller Sequenzen («sequence reads») eine Analyse in sehr hoher Auflösung, während die Sanger-Sequenzierung nur einen «Durchschnittswert» pro Nukleotidposition zulässt - dadurch bietet die NGS-Technik einen erheblich höheren Informationsgewinn. Waren die NGSSequenzierer der ersten Generation noch sehr teuer und von begrenzter Kapazität, verfügen die aktuellen Geräte über eine sehr viel höhere Kapazität, die ein kostengünstiges Durchführen der molekularen Diagnostik erlauben. In vielen pathologischen Instituten kommt neben der MiSeq (Illumina) die Ion Torrent Personal Genome Machine (PGM; ThermoFisher) für die AmplikonNGS zum Einsatz. Der PGM kommt mit sehr wenig DNAProbenmaterial (10 ng oder weniger) aus und kann für die Ana- 


\section{Berlin, Juni 2015}

\section{Statistik zum Ringversuch BRCA1/2-Diagnostik vorgelegt}

31 Institute nahmen am Ersten Nationalen Ringversuch zur molekularpathologischen BRCA1/2-Diagnostik teil, davon 26 erfolgreich (83\%). Insgesamt schnitten 19 deutsche Institute, sechs schweizerische und ein österreichisches Institut mit Punktzahlen zwischen 18 und 20 hervorragend ab. In Deutschland wurde sogar fast immer die Höchstpunktzahl erreicht. Damit bietet die deutsche Pathologie molekularpathologische BRCA-Diagnostik flächendeckend und vor allem auch in geprüfter Qualität an. Den erfolgreichen Instituten gratulieren wir herzlich!

Abb. 3. Ringversuch zur NGS-Diagnostik auf $B R C A-M u t a t i o n e n$. Quelle: pathologie-dgp.de.

lyse verschiedener Multigen-Panels (z.B. Colon Lung Panel V2, Cancer Hot Spot, BRCA1/2 sowie ein RNA-Fusionsgen-Panel) genutzt werden.

Um die Zuverlässigkeit der Amplikon-NGS zu prüfen, wurden im Rahmen des Deutsche Konsortiums für Translationale Krebsforschung (DKTK) mehrere molekularpathologische Labore um die NGS-Befundung von 15 mit der Sanger-Sequenzierung molekular vorcharakterisierten Tumorproben gebeten. Die vergleichenden Untersuchungen haben eine praktisch komplette Übereinstimmung der verschiedenen NGS-Plattformen (ThermoFisher, Illumina) bei der Detektion von Mutationen und deren Positionierung ergeben. Darüber hinaus war die Übereinstimmung unabhängig davon, an welchem der verschiedenen Standorte die Analysen durchgeführt wurden. Auch die Sensitivität der Methoden, gemessen am Beispiel einer Zelllinienverdünnung, wies bei den komplexen und doch recht heterogenen Technologien eine bemerkenswert hohe Vergleichbarkeit auf.

Seit der Umstellung von der Sanger-Sequenzierung auf die Amplikon-basierte NGS mit der PGM-Technologie im Jahr 2014 wurden in der Charité bereits mehr als 2500 Sequenzierungen damit vorgenommen. Derzeit erfolgt der Umstieg auf die nächste Gerätegeneration (Thermo Fisher S5XL), die in der Lage ist, noch komplexere Gen-Panels zu verarbeiten und gleichzeitig RNAAnalysen zum Nachweis von Fusionsgenen durchzuführen. So deckt etwa der Oncomine ${ }^{\mathrm{TM}}$ Focus Assay insgesamt 52 Gene bzw. Target-Gene ab. Noch komplexer ist der Oncomine ${ }^{\mathrm{TM}}$ Comprehensive Assay, der 143 Gene/Targets berücksichtigt. Natürlich lassen sich mit den NGS-Geräten der neuen Generation auch sehr große Gene wie BRCA1 und BRCA2 komplett sequenzieren, um daraus Therapieempfehlungen bezüglich einer möglichen Therapie mit PARP-Inhibitoren abzuleiten $[15,16]$.

Um die diagnostische Zuverlässigkeit der BRCA-Gentestung an Tumorproben des hochmalignen serösen Ovarialkarzinom zu überprüfen, hat die Deutsche Gesellschaft für Pathologie (DGP; Qualitätsinitiative in der Pathologie (QuiP)) im Jahr 2015 einen Ringversuch gestartet. Hierfür wurden von fünf deutschen molekularpathologischen Laboren insgesamt zehn Gewebeproben (4× BRCA1-mutiert, $3 \times$ BRCA2-mutiert, $3 \times$ nicht mutiert) zusammengestellt und für eine gegenseitige verblindete Testung verwen- det. Nach Feststellung der Übereinstimmung der Befunde wurde ein internationaler Ringversuch mit 26 Laboren aus Deutschland, Österreich und der Schweiz initiiert, den 85\% der Teilnehmer aufgrund der korrekten Ergebnisse bestanden haben (Abb. 3). Somit kann die molekularpathologische BRCA-Diagnostik nunmehr flächendeckend und in geprüfter Qualität angeboten werden.

Eine neue Herausforderung ist die Detektion von TumorDNA-Mutationen, z.B. EGFR-T790M, im peripheren Blut. Für diesen Nachweis, der häufig mit dem Begriff «Liquid Biopsy» [17] umschrieben wird, sind verschiedene Besonderheiten zu berücksichtigen. So ist der Nachweis von Tumor-DNA im Blutplasma zeitlich sehr begrenzt [18]: Bereits nach wenigen Stunden ist die Tumor-DNA, die meist nur in sehr geringen Mengen vorliegt, durch freigesetzte DNA aus Nicht-Tumorzellen des Bluts nahezu vollständig überdeckt, und die Tumor-spezifischen DNA-Veränderungen sind nicht mehr zuverlässig nachweisbar. Außerdem ist es erforderlich, das Mutationsmuster des Tumorgewebes als «Referenz» heranzuziehen [19]. Bei einem ausbleibenden Nachweis einer EGFR-T790M-Mutation im Blut kann ohne parallelen Nachweis anderer tumorspezifischer Mutationen nicht ausgeschlossen werden, dass keine bzw. keine ausreichende Menge an Tumor-DNA im Plasma vorhanden war. Um die Bearbeitungszeiten von Blutproben ohne nennenswerten Qualitätsverlust verlängern zu können, gibt es spezielle Blutabnahmesysteme (K(3) EDTA and Cell-Free DNA ${ }^{\mathrm{TM}}$ BCT) [20]. Um die Zuverlässigkeit des Nachweises zellfreier Tumor-DNA in Blutproben in verschiedenen molekularpathologischen Laboratorien zu testen, wurde von der QuiP ein entsprechender Ringversuch initiiert und durchgeführt. Hierfür wurden verschiedene entsprechend vorbereitete Zelllinien-DNA in absteigenden Konzentrationen in $10 \mathrm{ml}$ Vollblut gegeben, so dass nach Aufarbeitung nur noch wenige Kopien mutierte DNA in der für die NGS eingesetzten Probe vorhanden waren. Dennoch wurden die EGFR-T790M-Mutation sowie andere Mutationen zuverlässig nachgewiesen.

Auch vor der Klonalitätsanalyse hat die NGS-Technik nicht Halt gemacht. So lässt sich z.B. die Gesamtheit der T-ZellRezeptor-beta(TCR- $\beta$ )-Genumlagerungen einer Probe mittels einer Multiplex-PCR mit 58 verschiedenen Primern amplifizieren und mittels NGS individuell sequenzieren. Das erlaubt, die einzelnen Sequenzen jeder TCR- $\beta$-Umlagerung abzulesen sowie die Häufigkeit der Umlagerungen zu quantifizieren [21]. Damit ist es möglich, aus einer Blut- oder Gewebeprobe die individuelle Sequenz jedes einzelnen TCR- $\beta$ zu bestimmen. Diese Vorgehensweise lässt sich einsetzen, um

- die Klonalität mit wesentlich höherer Auflösung zu bestimmen,

- Klonalitäten aus verschiedenen Proben des gleichen Patienten - auch im zeitlichen Verlauf - zu vergleichen,

- T-Zell-Muster bzw. deren Diversität mit verschiedenen Erkrankungen/Krankheitsverläufen zu korrelieren sowie

- minimale Tumorreste im Blut als Therapiekontrolle nachzuweisen.

Diese und weitere Beispiele belegen, dass die Amplikon-NGS heute zuverlässige und klinisch/therapeutisch entscheidende Ergebnisse liefert und ein für die molekularpathologische Diagnos- 


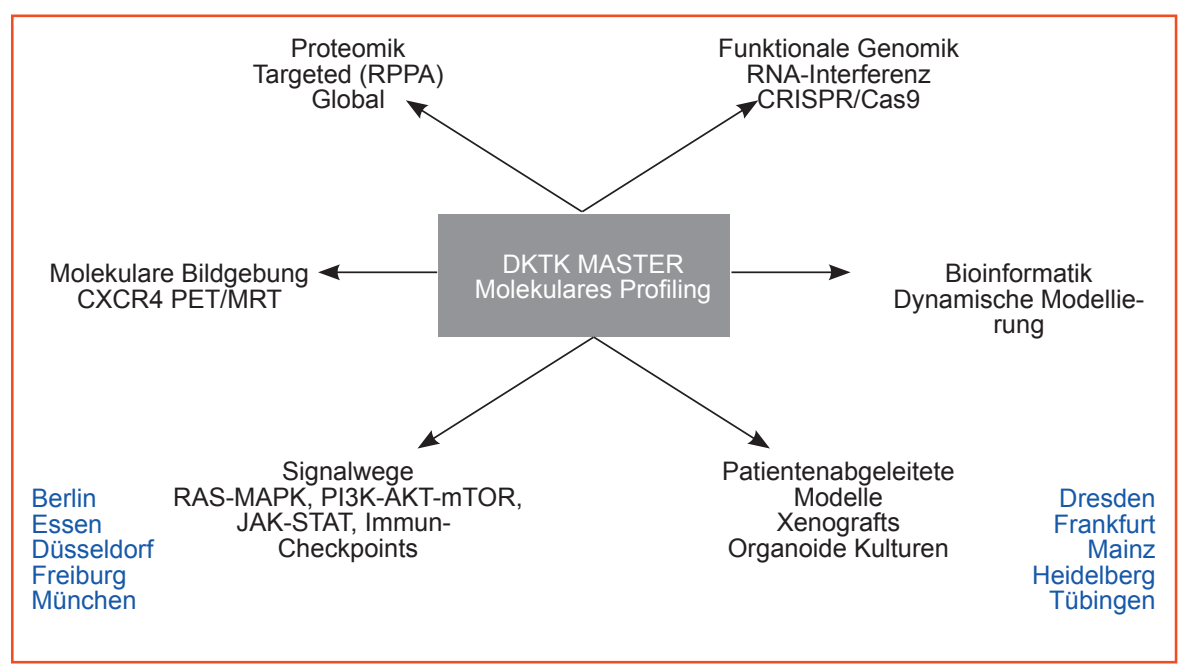

Abb. 4. Arbeitsfelder innerhalb des DKTKMaster-Programms.

Im Rahmen des Precision Oncology Program am Nationalen

tik taugliches Tool ist. Sie ermöglicht eine molekulare Analyse sowohl unter Verwendung von DNA als auch von RNA, die sowohl aus formalinfixierten als auch aus unfixierten Proben stammen können. Es darf jedoch nicht außer Acht gelassen werden, dass die NGS ein komplexes molekularbiologisches Verfahren darstellt, für dessen fachgerechte Durchführung ebenso wie für die korrekte Interpretation der gewonnenen Ergebnisse hervorragend ausgebildetes und erfahrenes technisches und wissenschaftliches Personal benötigt wird. Die Ergebnismitteilung der molekularen Befunde muss umfassend und gut verständlich abgefasst sein. Nur in diesem Zusammenspiel aller Komponenten entsteht eine hoch zuverlässige Datengrundlage, die für die therapeutische Entscheidung herangezogen werden kann.

\section{Status der molekulargenetischen Diagnostik - Stellenwert der molekularen Diagnostik aus Sicht des Onkologen}

\section{Referent: Christof von Kalle, Heidelberg}

Die Onkologie hat in den letzten Jahren eine Art Paradigmenwechsel hin zu einer stärker individualisierten Therapie vollzogen. Wesentliche Voraussetzung dafür war die Entwicklung hochauflösender molekularer Analyse-Verfahren auf intrazellulärer Ebene und die zunehmende Erschwinglichkeit von breit angelegten Sequenzierverfahren. Die molekulargenetische Diagnostik ist ein Teil dieser Entwicklung, die sich auf dem Gebiet der Proteomik und anderer hochauflösender Verfahren noch weiter fortsetzen wird. Im Rahmen einer Meta-Analyse [22] konnte gezeigt werden, dass individualisierte Krebstherapien Vorteile hinsichtlich höherer Response-Raten und einer verminderten Toxizität gegenüber einer konventionellen Chemotherapie haben, insbesondere wenn genetische Informationen bei der Therapiewahl berücksichtigt werden. Die Targeted Therapies schnitten jedoch vergleichsweise schlecht ab, wenn sie unselektiert eingesetzt wurden.
Centrum für Tumorerkrankungen (NCT) Heidelberg wird bei ausgewählten Krebspatienten eine breite molekulare Stratifizierung mit dem Ziel vorgenommen, sowohl die Diagnostik als auch die Therapie für jeden einzelnen Patienten zu verbessern. Dafür arbeiten Molekularbiologen, Bioinformatiker und Kliniker eng zusammen. Der daraus entstandene NCT-Master-Workflow ist in der Lage, Fragen von hoher Komplexität zu beantworten. Der hohe Durchsatz ist in der Genom-Analytik jedoch auch eine Frage der Infrastruktur - wir haben zusammen mit dem Deutschen Konsortium für Translationale Krebsforschung (DKTK) deshalb eine Einheit geschaffen, die für Forschungsansätze die benötigte Hochdurchsatz-Analytik bis hin zur Gesamt-Genom-Sequenzierung anbieten kann. Aus dem Workflow leiten wir darüber hinaus Registerstudien und Basket-Studien ab, in denen Krebserkrankungen unterschiedlicher Lokalisation, aber mit gleichem Mutationsmuster «in einen Topf geworfen» und einheitlich molekularbasiert therapiert werden. Vor allem «seltene» Erkrankungen, die in der Gesamtheit gar nicht so selten sind, können von diesen Ansätzen profitieren. Im Folgenden leiten wir aus diesem Workflow funktionelle Forschungsansätze ab, die generelle Erkenntnisse in der Molekularbiologie von Krebserkrankungen versprechen und können dabei auf Datensätze von aktuell etwa 500 Patienten zurückgreifen. Bei etwa einem Viertel der Patienten mit einer molekular basierten Empfehlung führt die molekulare Stratifizierung zu Änderungen im Therapieplan; in ähnlicher Größenordnung ist dies in anderen Programmen (Mi-Oncoseq, UCSD PREDICT) der Fall. Unser hiesiges Programm wird nun kontinuierlich zu einem multizentrischen Projekt innerhalb des DKTK ausgebaut, damit einerseits auch externe Patienten einfacher daran teilnehmen können und andererseits dieses als DKTK Master «Molecular Profiling» bezeichnete Programm für Forschungsarbeiten außerhalb des NCT genutzt werden kann (Abb. 4). Entsprechend der Expertise der Projektteilnehmer beziehen sich die Arbeiten nicht nur auf die Genomik, sondern auch auf die Bioinformatik, die Proteomik und andere molekularbiologische Arbeitsbereiche. In der onkologischen Pädiatrie wurde im Übrigen schon früh mit dem Projekt 
Abb. 5. Das Erfassen von Patientendaten beim derzeitigen Szenario fehlt eine übergeordnete Daten-Plattform.
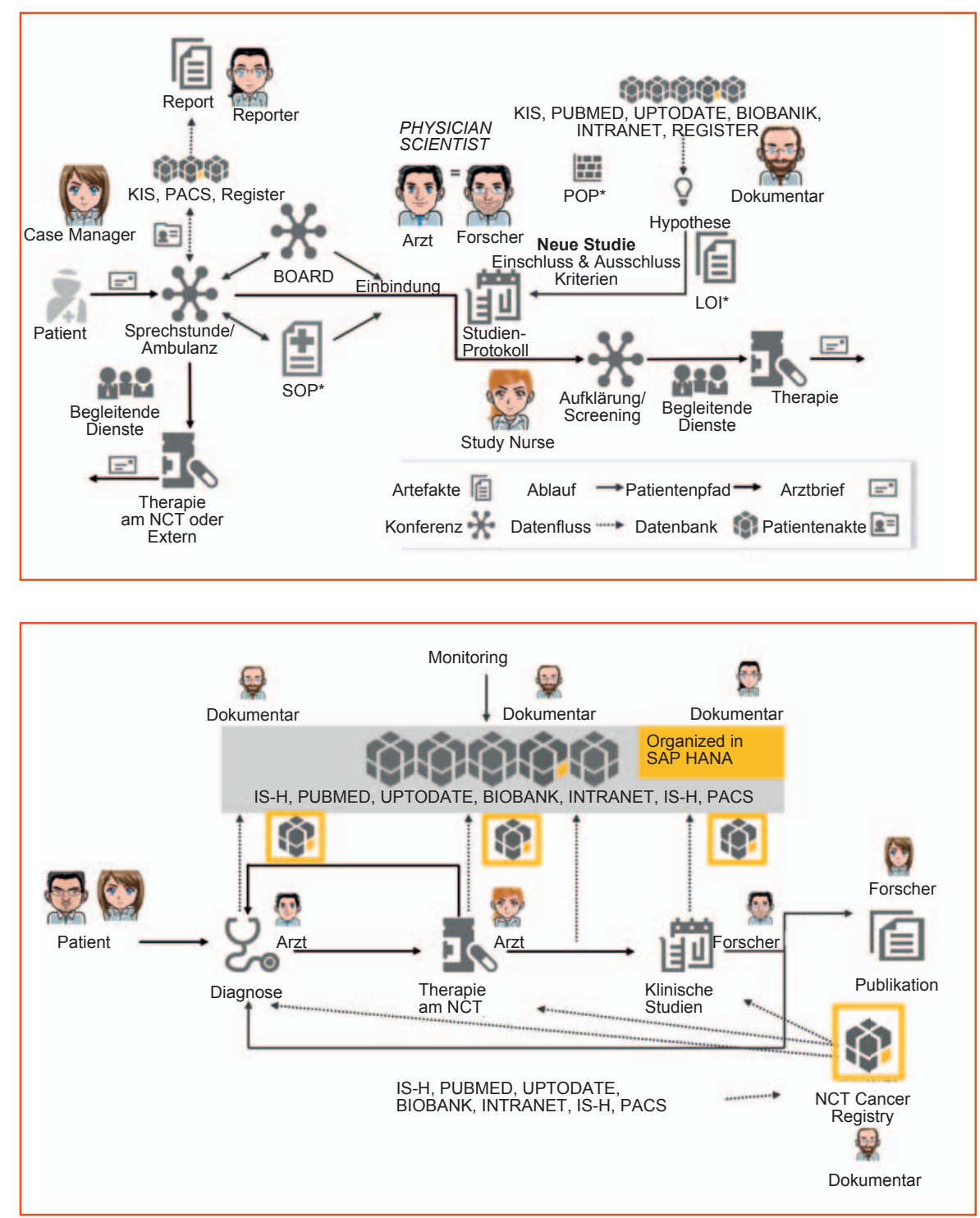

Abb. 6. Das Erfassen von Patientendaten - am NCT werden Daten in einer Cloud gespeichert.

Die weiteren Möglichkeiten der genomischen Diagnostik auch

INFORM (INdividualized therapy FOr Relapsed Malignancies in childhood) eine ähnliche Plattform geschaffen, die unter anderem die Möglichkeit bietet, alle Kinder mit einem Tumorrezidiv molekulargenetisch zu untersuchen.

Es gehört zur Aufgabe der medizinischen Grundlagenforschung, ihre Ergebnisse möglichst schnell in einen klinischen Kontext zu stellen. Die Verbindung zwischen Forschung und Klinik wird über die NCT-Datenbank DataThereHouse gewährleistet. Diese Datenbank ermöglicht einen Überblick über sämtliche Daten und Befunde eines Patienten und dient als Grundlage für die Erstellung eines individualisierten Therapieplans. Während bisher eine Vielzahl von Patienteninformationen erst relativ spät im Krankheitsverlauf in Form von Registern erfasst wurde (Abb. 5), sollten diese künftig parallel unter Wahrung des Datenschutzes in einem zentralen System abgespeichert und allen in die Patientenversorgung involvierten Berufsgruppen zugänglich gemacht werden (Abb. 6). Dies ist der Erfahrung geschuldet, dass Rohdaten - etwa aus dem Genlabor - nur im Kontext mit den klinischen Befunden aussagekräftig sind. im subgenomischen Bereich lassen sich gut an den Forschungsaktivitäten im Bereich des Lungenkarzinoms verdeutlichen. Den hohen Benefit für die Patienten, z.B. durch EGFR-Mutationstestung, lässt sich nur schätzen [23]: Ausgehend von jährlich rund 52000 Patienten mit NSCLC, könnten durch Erhöhung der EGFR-Anlayserate von derzeit 52\% auf $100 \%$ etwa 3500 zusätzliche Lebensjahre aufgrund einer individualisierten Therapie erreicht werden.

Vor allem beim Lungenkrebs hat sich das genomische Wissen bezüglich möglicher Treibermutationen in den letzten Jahren enorm erweitert und zu einer Stratifizierung der Patienten in verschiedene Untergruppen geführt. Mittlerweile gibt es für mehr als die Hälfte der NSCLC-Patienten molekular definierte Therapieoptionen. Parallel dazu hat sich die molekulare Diagnostik etwa durch Nutzung von Anreicherungssequenzier-Verfahren technisch weiterentwickelt [24]. Dass eine mutationsspezifische Therapie die Therapieergebnisse wesentlich verbessert, konnte unter anderem für die Anwendung von Crizotinib bei Patienten 
mit ROS1-mutiertem NSCLC gezeigt werden [25]. Dies gilt nicht nur für die Therapie mit «small molecules» wie den TKIs, sondern auch für die Immuntherapie: Retrospektiven Studien zufolge scheint die Mutationslast eine prädiktiver Marker für das Ansprechen auf den Antikörper Ipilimumab beim metastastierten Melanom [26] bzw. für das Pembrolizumab-Ansprechen bei NSCLC zu sein [27].

In Zukunft dürften zusätzlich vermehrt Substanzbibliotheken an primärem Material getestet werden um zu sehen, wie die zu untersuchenden Zellen phänotypisch auf solche Blockaden reagieren. Dadurch könnte es möglich sein, Tumoren aufgrund ihrer Substanzsensitivität in weitere Subgruppen zu unterteilen. Dabei darf nicht vergessen werden, dass durch die Möglichkeit der Genom-Editierung (dem gezielten Einbringen von Mutationen über sich schnell verändernde RNA-Abschnitte) die Forschung rasch vorangetrieben wird. In vitro neu identifizierte Auffälligkeiten können in kurzer Zeit auf ihre klinische Relevanz überprüft und entsprechende Studien in Gang gebracht werden. Dies gilt etwa für den Nachweis der CDK6-Inhibtion in MLL-Fusionsproteinen [28], die kurze Zeit später zur Initiierung einer klinischen Studie bei Patienten mit akuter myeloischer Leukämie (AML) und MLL-Veränderungen geführt hat. Auch wenn die molekulare Diagnostik durch die aufwändige Datengenerierung und -auswertung noch nicht überall problemlos in den klinischen Alltag integriert werden kann, wird die Molekulargenetik zu einem Werkzeug, das den Patienten über eine bessere Stratifizierung einen Nutzen auch da verspricht, wo es bisher keine effektiven Therapien gab.

\section{Überschneidung von Tumor- und Keimbahn- diagnostik - BRCA-Mutationsanalyse bei Ovarial- und Mammakarzinomen}

\section{Referentin: Rita Schmutzler, Köln}

Wird bei einer an einem Ovarial- oder Mammakarzinom erkrankten Patientin eine Mutation der Tumorsuppressorgene BRCA1/2 im Tumorgewebe nachgewiesen, kann diese sowohl auf einer somatischen Neumutation im Tumor als auch auf einer Keimbahnmutation beruhen. BRCA1/2-assozierte Tumoren mit Keimbahnmutation weisen histopathologische Besonderheiten auf, sie haben ein distinktes molekularpathologisches Profil und sprechen spezifisch auf BRCA-schädigende Substanzen wie PARP-Inhibitor an. Tumoren, in denen keine Keimbahnmutation nachweisbar ist, sondern lediglich eine somatische (folglich nicht hereditäre) Phänokopie einer BRCA1/2-Mutation, werden als BRCAness-Tumoren bezeichnet.

Die spezifische Therapie sowohl bei BRCA1/2-assoziierten Tumoren als auch bei BRCAness-Tumoren besteht in der Behandlung mit PARP-Inhibitoren. Zellen mit mutiertem BRCA1/2-Gen haben dysfunktionale DNA-Reparaturmechanismen [29]: Bei DNA-Strangbrüchen während der Zellreplikation erfolgt keine homologe Rekombination, sondern die Zellen nutzen einen alter- nativen Weg mit Hilfe der Enzyme PARP1 und PARP2. Wird dieser Reparaturweg durch Gabe von PARP-Inhibitoren gehemmt, führt die dann irreversible DNA-Schädigung zum Absterben der Zelle durch Apoptose.

Frauen mit hereditärer BRCA1- oder BRCA2-Mutation haben ein erhöhtes Risiko für die Erkrankung an einem Mamma- und/ oder Ovarialkarzinom. Der PARP-Inhibitor Olaparib (Lynparza ${ }^{\circledR}$ ) ist von der European Medicines Agency für die Erhaltungstherapie beim fortgeschrittenen Ovarialkarzinom (hochgradig, serös) nach Ansprechen auf eine platinhaltige Chemotherapie bei Patientinnen mit Nachweis einer BRCA-Mutation zugelassen.

Der Nachweis einer $\mathrm{t} B R C A$-Mutation (Tumor-BRCA-Mutation) kann sich auf beide Mutationsarten beziehen. Eine sichere Differenzierung wird mit der Untersuchung nicht bezweckt, da es - wie bei Olaparib - lediglich um die Klärung der Erfüllung der Zulassungsvoraussetzungen für eine Arzneimittelanwendung geht. Da der Untersuchungszweck mithin nicht auf den Nachweis einer Keimbahnmutation gerichtet ist, fällt die Untersuchung am Tumorgewebe nach überwiegender Auffassung nicht unter die besonderen Anforderungen des Gendiagnostikgesetzes (GenDG; www.gesetze-im-internet.de/gendg/) [30]. Andererseits ist die weit überwiegende Zahl der detektierten BRCA1/2-Mutationen im Tumorgewebe auf eine Keimbahnmutation zurückzuführen. Dies hat sich in einer ersten translationalen Studie bestätigt, deren Ergebnisse demnächst veröffentlicht werden (ASCO 2016).

$B R C A$-Mutationsuntersuchungen mit Einbeziehung der Keimbahn unterliegen dem GenDG. Dieses sieht eine Aufklärungspflicht vor $(\$ \$ 8,9,10 \mathrm{GenDG})$. Dadurch soll die Patientin vor einer ungewollten Konfrontation mit belastenden Untersuchungsergebnissen bewahrt, ihr Recht auf informationelle Selbstbestimmung gewahrt und sie vor Benachteiligung durch Dritte (Versicherer) geschützt werden. Die Patientin soll nach entsprechender Information im Vorfeld selber entscheiden, ob und in welche Untersuchungen sie einwilligt und welche möglichen Ergebnisse sie wissen möchte.

$\mathrm{Zu}$ dieser Problematik heißt es in einer aktuellen wissenschaftlichen Publikation [31]: «Eine rechtssichere Lösung lässt sich daher für somatische genetische Veränderungen, die Rückschlüsse auf Keimbahnmutationen zulassen, auf der Grundlage des geltenden Rechts nicht konstruieren. Daher wäre es wünschenswert, wenn der Gesetzgeber die Anwendbarkeit des GenDG auch in diesen Fällen ausdrücklich klarstellen würde, um dem Schutz der Betroffenen und ihrer Daten Rechnung zu tragen, zumal die einschlägig interessierten Kreise - etwa Versicherungen - bereits mit Wahrscheinlichkeitsinformationen arbeiten können und keine 100\%ige Sicherheit über das Vorliegen einer Keimbahnmutation benötigen.»

Eine weitere Herausforderung in der BRCA-Mutationsanalyse besteht in der pathogenetischen Einordnung der gefundenen $\mathrm{Mu}$ tationen. Hilfreich ist das fünfstufige IARC-Klassifikationssystem [32-34]. Darin gibt es zu jeder Klasse Angaben, mit welcher Wahrscheinlichkeit die gefundenen Varianten pathogen sind. Probleme bereiten Mutationen der Klasse 3 («uncertain pathoge- 


\section{NGS auf BRCA1/2-Mutationen - Auswertungen des deutschen Konsortiums}

$>20000$ getestete Familien

5130 Familien mit pathogener Mutation

- $16 \%$ der pathogenen Mutationen sind mit alleiniger NGS nicht nachweisbar bzw. nicht sicher einzuordnen (große Rearrangements und potentielle Spleißmutationen)

Die NGS im Tumor MUSS durch eine CNV-Analyse im Blut ergänzt werden (RiLiBÄK)

Abb. 7. Limitierungen des NGS bei der Analyse von BRCA1/2-Mutationen.

nic»), denen eine Pathogenität von 5-95\% zugeschrieben wird und die als Varianten unklarer Signifikanz (VUS) geführt werden.

Nach umfangreichen Daten, die das Deutsche Konsortium für Familiären Brust- und Eierstockkrebs erhoben hat, beträgt der Anteil an VUS für jedes neu identifizierte Tumorsuppressor-Gen 20-30\%, z.B. weil die funktionellen Domänen im Gen noch nicht vollständig beschrieben sind. Bezogen auf das BRCA1/2-Gen trifft die Klassifizierungsstufe 3 nur noch auf weniger als 5\% der Mutationen zu. Zu verdanken ist dies einer guten Aufarbeitung und Dokumentation der gefundenen Mutationen in Datenbanken.

Im Hinblick auf die Schwierigkeiten im Umgang mit den doch zahlreichen VUS im Zuge einer breiter angelegten Gendiagnostik haben wir den Nutzen häufig verwendeter Mutationsprädiktionsprogramme geprüft. Als Datenpool wurde die Datenbank des Deutschen Konsortiums für Familiären Brust- und Eierstockkrebs verwendet, die über 23000 genetische Familienanamnesen (davon etwa 4500 BRCA1/2-positive Diagnosen) enthält. Von den gefundenen 669 «Missense»-Varianten waren 119 eindeutig pathologisch neutral, 39 eindeutig pathogen und 511 hinsichtlich ihrer Pathogenität nicht einzuordnen (VUS; Stufe 3). Die Klassifizierung der Varianten wurden mit den Vorhersageprogrammen PolyPhen-2, SIFT und MutationTaster überprüft. Alle 39 pathogenen Varianten wurden von den Programmen richtig erkannt, wobei das übereinstimmende Ergebnis von zwei Programmen für die Klassifizierung verwendet wurde. Jedoch wurden 35 der insgesamt 119 eindeutig neutralen Varianten von mindestens zwei Programmen als pathogen bewertet; dies würde bedeuten, dass fast 10000 Familien einen positiven Mutationsnachweis erhalten hätten. Die Aussagekraft solcher Programme ist deshalb indiskutabel.

Eine Mutationsanalyse durch alleinige Anwendung des NGS im Tumorgewebe ist problematisch, denn es werden sogenannte «large genomic rearrangements» - das sind große Duplikationen oder Deletionen in den Genen - nicht vollständig miterfasst. Des Weiteren können potentielle Spleißmutationen nicht weiter überprüft werden.

Das deutsche Konsortium für Familiären Brust- und Eierstockkrebs hat daher eine Auswertung der bis dato vorliegenden über 20000 Genanalysen zur familiären BRCA1/2-Mutationslast vorgenommen. Bei 5130 Familien wurde eine eindeutig krankheitsauslösende Mutation nachgewiesen. Die detaillierte Untersu-

\section{Beschleunigte Zulassung von Arzneimitteln: Individualized Cancer Treatment}

\begin{tabular}{|c|c|}
\hline \multicolumn{2}{|c|}{$\begin{array}{l}\text { Olaparib bei BRCA-Mutationen, Platin-sensitivem } \\
\text { Ovarialkarzinom }\end{array}$} \\
\hline $\begin{array}{l}\text { - neues Wirkprinzip } \\
\text { - Personalisierte Medizin } \\
\text { - Somatische und } \\
\text { Keimbahnmutationen in } \\
\text { BRCA-Genen } \\
\text { (Brustkrebsrisiko) }\end{array}$ & $\begin{array}{l}\text { Leukämie-Fälle doppelt so häufig unter } \\
\text { Therapie, bereits nach 0,5-2 Jahren } \\
\text { Mechanismus? Risikogruppen? }\end{array}$ \\
\hline $\begin{array}{l}\text { Vorlaufforschung } \\
\text { Pharmakovigilanz } \\
\text { Risikosignalerkennung } \\
\text { Patientenrisikogruppen }\end{array}$ & $\begin{array}{l}\text { Studie zur Langzeit-Sicherheit und } \\
\text { Wirksamkeit von DNA-schädigenden } \\
\text { Agenzien } \\
\text { - Gesamtüberleben, Lebensqualität } \\
\text { - Exposition an genotoxischen Sub- } \\
\text { stanzen/Strahlung } \\
\text { - Auftreten von hämatologischen } \\
\text { Zweiterkrankungen (MDS/AML) } \\
\text { - Biomarker: Klonale Hämatopoese }\end{array}$ \\
\hline
\end{tabular}

Abb. 8. Verlaufsforschung vor dem Hintergrund gemeldeter Leukämie-Fälle unter Olaparib (nach Informationen des BfArM).

chung des Mutationstyps hat ergeben, dass rund 16\% dieser Mutationen mit dem NGS-Verfahren nicht nachweisbar bzw. nicht eindeutig einzuordnen sind (Abb. 7). Bei alleiniger NGS-Analyse wird also einem erheblichen Teil der Patientinnen eine Therapie mit Olaparib vorenthalten.

Für eine vollständige $B R C A 1 / 2$-Analyse ist es wichtig, auch beide, die somatischen Mutationen sowie die «large rearrangements», zu erfassen. Ihr Anteil beträgt 3-4\% (somatische Mutationen) bzw. etwa $2 \%$ («large rearrangements»). Eine zweifache Analyse sowohl im Tumorgewebe als auch im Blut ist deshalb eigentlich unerlässlich; zumindest jedoch sollte im gendiagnostischen Befund vermerkt sein, welche Untersuchungen durchgeführt worden sind.

Das deutsche Konsortium für Familiären Brust- und Eierstockkrebs hat ein Konzept zur kombinierten Blut/Tumor-Analyse entwickelt, das den Herausforderungen an eine möglichst vollständige Diagnostik gerecht wird. Dazu gehört auch die Einbindung der behandelnden Ärzte als Kooperationspartner in die Aufklärung zur diagnostischen genetischen Testung und die enge Absprache bei der Interpretation der Genbefunde, für die das Konsortium derzeit eine flächendeckende Fortbildung aufbaut.

Entsprechend einer Richtlinie der Bundesärztekammer (RiLiBÄK) muss die Mutationsuntersuchung durch Analyse der «copy number variation» (CNV) im Blut ergänzt werden.

Für die Therapie von Frauen mit Ovarialkarzinom ist zu beachten, dass die Inhibition der PARP-Enzyme nur dann greift, wenn beide Allele der Tumorsuppressor-Gene BRCA1 und $B R C A 2$ ausgeschaltet sind, z.B. durch eine ererbte Mutation in einem Allel und eine weitere zufällige Mutation im zweiten Allel ( «loss of heterozygosity»; LOH). Bei heterozygoter BRCA1/2-Mutation in der Keimbahn wirken PARP-Inhibitoren nicht. Es stellt sich jedoch die Frage, ob bei Nachweis einer singulären somatischen Mutation in einem Tumor die PARP-Inhibition eine effektive Option sein kann. Wir untersuchten dafür Tumorgewebe 


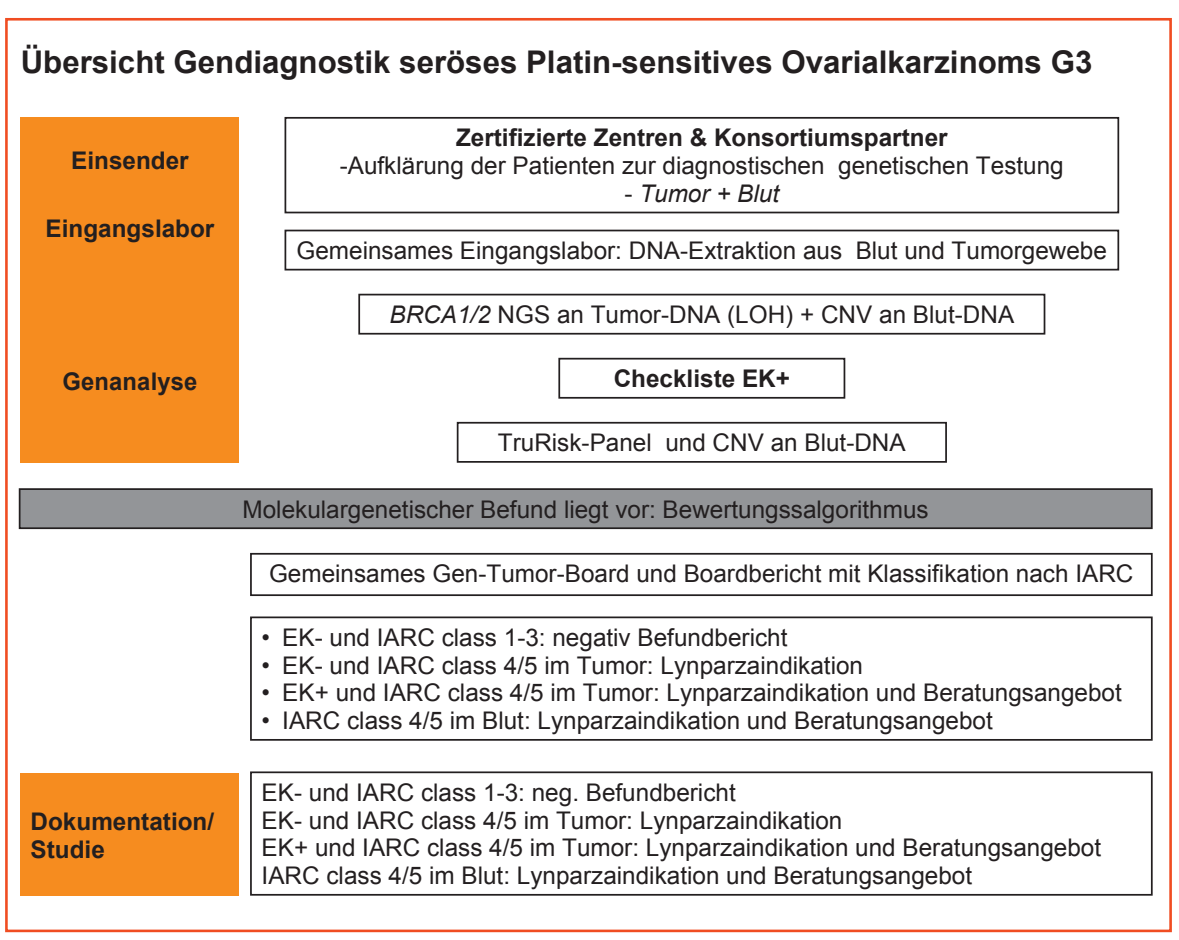

Abb. 9. Vorgehen zur Gendiagnostik beim serösen Platin-sensitiven Ovarialkarzinom.

und Blutproben von 109 Frauen mit Ovarialkarzinom und einer BRCA1/2-Keimbahnmutation. Bei den meisten Frauen betrug der Anteil mutierter Allele («allele read fraction») im Blut etwa 50\%; es handelte sich also um eine heterozygote Mutation. In den NGS-Analysen im Tumorgewebe fanden sich jedoch teils deutlich höhere Anteile an mutierten Genen; es müssen also im Gewebe zufällige somatische Mutationen (LOH) stattgefunden haben, die die Tumorentwicklung in Gang gesetzt haben. Diese somatischen BRCA1/2-Mutationen haben eine hohe Varianz und sind mit einem «allele read fraction»-Anteil zwischen 10 und $80 \%$ im Tumorgewebe nachzuweisen. $\mathrm{Ob}$ das Ansprechen auf PARPInhibitoren mit dem Ausmaß der «allele read fraction» korreliert, ist Gegenstand weiterer Untersuchungen.

Bekannt ist ferner, dass bei heterozygotem BRCA1/2-Mutationsstatus die DNA-Reparaturkapazität durch Haploinsuffizienz herabgesetzt sein kann. Dies konnte in vitro durch Lymphozytenbestrahlung derartig mutierter Zellen simuliert werden: Die Zellen von Mutationsträgerinnen zeigten nach Bestrahlung eine deutlich erhöhte chromosomale Instabilität im Vergleich $\mathrm{zu}$ nichtmutieren Zellen. Eine solche Instabilität könnte die Entwicklung von Zweittumoren unter PARP-Inhibition triggern, wie dies für die AML gezeigt werden konnte: Bei Vorliegen einer BRCA1/2-Mutation betrug das AML-Risiko unter PARP-Therapie etwa $1 \%$ im Vergleich zu $0,6 \%$ bei negativem BRCA1/2-Mutationsbefund. Auch das Tumorrisiko unter anderen DNA-schädigenden Tumortherapien des Ovarialkarzinoms, etwa die Chemotherapie mit Platinderivaten, scheinen nach ersten Untersuchungen mit bestimmten Genmosaiken zu korrelieren, so dass die Gendiagnostik womöglich auch einen prädiktiven Wert zur Abschätzung des Malignomrisikos unter Therapie mit Platin oder Alkylanzien haben kann.
Die beschleunigte Zulassung neuer Arzneimittel zur individualisierten Krebstherapie zieht Studien zur Verlaufsforschung nach sich, um unter anderem das Risiko für hämatologische Zweiterkrankungen abzuklären (Abb. 8). In Zusammenarbeit mit dem Bundesinstitut für Arzneimittel und Medizinprodukte (BfArM) ist eine Langzeitbeobachtung zur Sicherheit und Wirksamkeit DNAschädigender Agenzien bei Patientinnen mit BRCA1/2-Mutationen geplant. Durch die enge Fokussierung auf die BRCA1/2-Mutationsträgerinnen sind relativ schnell Ergebnisse zu erwarten.

Da BRCA1/2 lediglich für etwa 30\% der hereditären Tumoren ursächlich ist [35], ist die Identifizierung weiterer Risikogene mittels Exom- und Gesamt-Genom-Sequenzierung eine wichtige Forschungsaufgabe. Nach derzeitigem Wissen gibt es eine Fülle weiterer Risikogene, die aber relativ selten mutiert sind und vermutlich überwiegend moderat penetrant sind. Das Deutsche Konsortium hat in das Genpanel TruRisk ${ }^{\circledR}$ insgesamt 34 mit Brustkrebs und Eierstockskrebs assoziierte Gene aufgenommen. Dieses Panel wurde an 574 Proben aus dem Kölner Patientenkollektiv überprüft. Alle Tumoren waren vorab negativ für BRCA1/2-Mutationen getestet, davon 256 triple-negative Mammakarzinome und 318 mit positiver Famailienanamnese sowohl für Mammakarzinome als auch für Ovarialkarzinome. Die gefundenen Mutationen ( $\mathrm{n}=10$ (3,9\%) in den triple-negativen Mammakarzinomen sowie $\mathrm{n}=41(12,9 \%)$ in den belasteten Familien) deuten auf eine relativ hohe Mutationslast hin. Zum Vergleich: Die BRCA1/2-Mutationsrate beträgt etwa $17,5 \%$ bei triple-negativen Karzinomen bzw. 25\% bei positiver Familienanamnese. Die gefundenen 14 Risikogene eignen sich somit als prädiktive Marker für eine intensivierte Krebsfrüherkennung sowie für die Abschätzung des Therapieansprechens auf PARP-Inhibitoren. Beides bedarf weiterer Untersuchungen. 
Aus diesen Überlegungen heraus haben das deutsche Konsortium für Familiären Brust- und Eierstockkrebs und die Krankenkassen ein Diagnostikkonzept entwickelt, für das bereits ein sektorenübergreifender Vertrag abgeschlossen wurde (Abb. 9).

Diesem Konzept folgend, stellt ein interdisziplinäres Gen-Tumor-Board die Interpretation des Genbefunds nach aktuellem Kenntnisstand sicher, um so Über- und Untertherapien zu vermeiden. Im Rahmen des Follow-up geht es unter anderem um die mögliche Wirksamkeit spezifischer Therapien auch bei somatischen Mutationen sowie um die Erfassung von Langzeit-Nebenwirkungen. Darüber hinaus wird eine sektorenübergreifende Kooperation inklusive strukturierter Fortbildungen als Basis der Zusammenarbeit mit zertifizierten Kooperationspartnern zur Stärkung der genetischen Literacy der behandelnden Ärzte angestrebt.

\section{Überschneidung von Tumor- und Keimbahndiagnostik - molekulare Diagnostik beim kolorektalen Karzinom}

\section{Referent: Andreas Block, Hamburg}

In einer interdisziplinären Sprechstunde beraten Fachärzte für Humangenetik gemeinsam mit Onkologen und Gastroenterologen am UCCH Ratsuchende zu hereditären Tumorerkrankungen. Im Rahmen dieser Sprechstunde werden jährlich etwa 200 Familien mit den Schwerpunkten Lynch-Syndrom, familiäre adenomatöse Polyposis (FAP), Li-Fraumeni-Syndrom und anderen erblich determinierten Erkrankungen betreut.

Mit etwa 60000 Neuerkrankungen pro Jahr ist der Darmkrebs eine der häufigsten Krebserkrankungen in Deutschland. Das Lebenszeitrisiko für Männer beträgt 6,9\%, das für Frauen ist mit 5,7\% nur unwesentlich geringer. Das relative Risiko für die Entstehung eines kolorektalen Karzinoms (CRC) ist bei familiärer Belastung deutlich höher, und zwar um den Faktor 2,3 bei einem erstgradig Verwandten mit CRC und um den Faktor 2 bei einem erstgradig Verwandten mit Adenomen des Darms. Etwa die Hälfte der kolorektalen Karzinome treten sporadisch auf, bei einem Viertel der kolorektalen Karzinome findet sich eine familiäre Häufung mit ungeklärtem genetischen Hintergrund, und bei den übrigen Patienten handelt es sich um nachweislich hereditäre Erkrankungen wie das Lynch-Syndrom, die FAP und die eher seltenen mixed und harmatomatösen Polyposis-Syndrome [36].

Das Lynch-Syndrom (auch hereditäres nichtpolypöses Kolonkarzinom-Syndrom, hereditary nonpolyposis colorectal cancer; HNPCC) ist das häufigste hereditäre CRC und macht etwa 6\% der CRC aus. Es entsteht aus rasch progredienten polypösen Vorstufen und kann außer im Dickdarm auch in anderen Darmabschnitten (Dünndarm), im Magen sowie im urogenitalen Bereich (Endometrium) zu malignen Erkrankungen führen [37]. Familien mit einer Häufung von Tumorerkrankungen an diesen Manifestationsorten sollten im Hinblick auf eine monogenetische Erkrankung und insbesondere auf das Lynch-Syndrom genetisch untersucht werden. Mutationsträger mit Lynch-Syndrom haben einen Defekt

\section{Amsterdam-II-Kriterien}

- $\geq 3$ Familienangehörige mit Lynch-assoziierten Karzinom1 und keine FAP

- und mindestens zwei aufeinanderfolgende Generationen

- und mindestens eine Diagnosestellung vor dem 50. Lebensjahr

\section{Revidierte Bethesda - Richtlinien}

- Patienten mit kolorektalem Karzinom vor dem 50. Lebensjahr

- oder Patienten mit synchronen oder metachronen

Lynch-assoziierten Karzinomen

- oder Patienten mit MSI-H Histologie CRC vor dem 60. Lebensjah

- oder Patienten mit CRC und Verwandten 1. Grades mit Lynch-assoziiertem

Karzinom vor dem 50. Lebensjahr

- oder Patienten mit CRC und $\geq 2$ Verwandte 1. oder 2. Grades mit Lynchassoziiertem Karzinomen

Abb. 10. Diagnose des Lynch-Syndroms nach klinischen Kriterien (modifiziert nach $[39,40]$.

im Mismatch-Reparatursystem (MMR) der DNA. Aufgrund dieser Keimbahnmutation können während der Replikation fehlerhaft synthetisierte DNA-Abschnitte nicht korrekt repariert werden. Dadurch kommt es zu einer Akkumulation genetischer Alterationen, die - sofern Tumorsuppressor-Gene oder Protoonkogene davon betroffen sind - zur Entwicklung maligner Tumoren führen können. Dies geschieht, wenn nicht nur das durch Keimbahnmutation veränderte Allel, sondern auch das noch intakte Allel durch eine im Sinne eines «Second hit» zufällige somatische Mutation, LOH oder Hypermethylierung geschädigt oder inaktiviert ist. Es entstehen dann Zellen vom Mutator-Phänotyp, der über MultistepKarzinogene zur Ausbildung eines Lynch-assoziierten Tumors mit Mikrosatelliteninstabilität (MSI) führt.

Eine MSI in DNA-Regionen mit repetitiven Sequenzen führt zu Ablesefehlern und erzeugt Amplifikate, die sich von denen im gesunden Gewebe unterscheiden, was diagnostisch genutzt werden kann. Der zusätzliche immunhistochemische Nachweis beim Lynch-Syndrom bezieht sich auf einzelne Bausteine des MMR und weist eine veränderte Proteinexpression aufgrund von Defekten im MLH1-, MSH2-, MSH6- oder PMS2-Gen nach. Diese MLH1- und MSH2-Gene sind beim Lynch-Syndrom nach Auflistung des Deutschen HNPCC-Konsortiums am häufigsten von Mutationen betroffen [38], allerdings ist die Pathogenität einer Reihe weiterer genetischer Alterationen noch nicht abschließend bewertet (Varianten unklarer Signifikanz).

Männliche Genträger mit Lynch-Syndrom haben ein Lebenszeitrisiko von $34-73 \%$, an einem CRC zu erkranken, bei Frauen beträgt das Lebenszeitrisiko 32-59\%. Frauen haben darüber hinaus ein substantiell erhöhtes Risiko für ein Endometriumkarzinom (39-50\%) sowie für ein Ovarialkarzinom (7-8\%). Auch das Lebenszeit-Risiko für Magenkarzinome, Nieren-/Harnleiterkarzinome, Gallengangskarzinome, Dünndarmkarzinome, ZNS-Tumoren und Pankreaskarzinome ist signifikant erhöht.

Die Diagnose Lynch-Syndrom wird klinisch gestellt, wenn die sogenannten Amsterdam-II-Kriterien erfüllt sind (Abb. 10). Die Amsterdam-Kriterien können jedoch wegen der geforderten Zahl von mindestens drei erkrankten Familienangehörigen häufig nicht angewandt werden. Alternativ kann die Diagnose mit Hilfe der revidierten 
Tab. 3. Seltene hereditäre gastrointestinale Tumorerkrankungen

\begin{tabular}{|c|c|c|c|c|}
\hline Erkrankung & Gen & Funktion & Pattern & Prädominanter Tumor \\
\hline MUTYH-assoziierte Polyposis (MAP) & MUTYH & $\begin{array}{l}\text { DNA-Glykosylase, } \\
\text { Reparatur oxidativer DNA Schäden }\end{array}$ & rezessiv & Kolon \\
\hline Polymerase proofreading assoziierte Polyposis (PPAP) & $\begin{array}{l}\text { POLE } \\
\text { POLD1 }\end{array}$ & $\begin{array}{l}\text { Proofreading - Domäne der } \\
\text { DNA-Polymerasen } \varepsilon \text { und } \delta\end{array}$ & dominant & $\begin{array}{l}\text { Kolon } \\
\text { Endometrium }\end{array}$ \\
\hline Familiäre juvenile Polyposis (FJP) & SMAD4 & Teil des TGF- $\beta$-Signalweges & dominant & gastrointestinal \\
\hline \multirow[t]{2}{*}{ Intestinale epitheliale Dysplasie (IED) } & EpCAM & $\begin{array}{l}\text { Zelladhäsionsmolekül, Fehlen kann } \\
\text { zu MSH2 Silencing führen }\end{array}$ & $\begin{array}{l}\text { dominant, } \\
\text { somatisch }\end{array}$ & gastrointestinal \\
\hline & BRAF & $\begin{array}{l}\text { MAPK-Signalweg } \\
\text { MLH1-Silencing }\end{array}$ & somatisch & Melanom \\
\hline
\end{tabular}

Tab. 4. Empfehlungen zur Surveillance bei seltenen genetischen Erkrankungen. $\mathrm{I}=$ Intervall, $\mathrm{B}=\mathrm{Be}-$ ginn (Lebensjahr)

\begin{tabular}{|c|c|c|c|}
\hline Syndrom & ÖGD & Koloskopie & Sonstiges \\
\hline FAP & $\begin{array}{l}\mathrm{I}: 1-3 \\
\mathrm{~B}: 20-25\end{array}$ & $\begin{array}{l}\mathrm{I}: 1-2 \\
\mathrm{~B}: 10-12\end{array}$ & $\begin{array}{l}\text { Beurteilung der Papille in Seitoptik; prophylaktische Kolektomie wenn möglich } \\
\text { nach der Pubertät; jährliche Pouchoskopie und Rektoskopie nach Kolektomie; } \\
\text { jährliche Schilddrüsensonographie (15. Lebensjahr), CAVE: Desmoidtumore }\end{array}$ \\
\hline AFAP & $\begin{array}{l}\mathrm{I}: 3 \\
\mathrm{~B}: 30\end{array}$ & $\begin{array}{l}\mathrm{I}: 1-2 \\
\mathrm{~B}: 15\end{array}$ & Siehe FAP \\
\hline MAP & $\begin{array}{l}\mathrm{I}: 1-3 \\
\mathrm{~B}: 25-30\end{array}$ & $\begin{array}{l}\text { I:1 } \\
\text { B:18-20 }\end{array}$ & $\begin{array}{l}\text { Prophylaktische Kolektomie, wenn die Polypen endoskopisch nicht mehr } \\
\text { beherrschbar sind. }\end{array}$ \\
\hline PJS & $\begin{array}{l}\mathrm{I}: 2-3 \mathrm{~J} \\
\mathrm{~B}: 10\end{array}$ & $\begin{array}{l}\mathrm{I}: 2-3 \\
\mathrm{~B}: 8-20+\end{array}$ & $\begin{array}{l}\text { Mammakarzinom-Screening zweimal/Jahr ab dem 25. Lebensjahr. Jährliche } \\
\text { Untersuchung der Hoden ab dem 10. Lebensjahr. Jährliche gynäkologische } \\
\text { Untersuchung ab dem 18. Lebensjahr. }\end{array}$ \\
\hline FJP & $\begin{array}{l}\mathrm{I}: 1-3 \\
\mathrm{~B}: 10-15\end{array}$ & $\begin{array}{l}\mathrm{I}: 2-3+ \\
\mathrm{B}: 10-15\end{array}$ & \\
\hline PPAP & $?$ & $?$ & $\begin{array}{l}\text { Anscheinend breites klinisches Spektrum, HNPCC-Phänotyp bis typische } \\
\text { adenomatöse Polypose. Berichtet: Duodenalkarzinom, Endometrium-Karzinom }\end{array}$ \\
\hline
\end{tabular}

Bethesda-Richtlinien gestellt werden (Abb. 10), die den Nachweis einer MSI bei Vorliegen lediglich einer CRC-Erkrankung vor dem 50. Lebensjahr erforderlich macht. Gleiches gilt für Patienten mit einem metachron aufgetretenen CRC und für CRC-Patienten mit muzinöser Histologie oder Lymphozyteninfiltraten im Tumorgewebe.

Patienten mit CRC, die die Diagnosekriterien nach Amsterdam II oder Bethesda nicht erfüllen, werden präferentiell leitlinienkonform therapiert und in die Nachsorge eingebunden; andernfalls erfolgen weiterführende molekulargenetische Untersuchungen auf Proteinexpressionsverlust und MSI sowie gegebenenfalls eine humangenetische Diagnostik und Beratung. Sie bezieht im Falle einer Keimbahnmutation auch die Angehörigen des Patienten ein, um weitere mögliche Mutationsträger zu identifizieren. Bei etwa 5\% der Patienten findet sich keine Keimbahnmutation; bei ihnen erfolgen bei starkem klinischen Verdacht auf eine hereditäre Krebserkrankung weitere genetische Analysen (MUTYH, SMAD4, POLE und POLD1), und sie erhalten eine spezifische Nach- bzw. Vorsorge in Anlehnung an das Lynch-Syndrom.

Ein Sonderfall ist der immunhistochemische Nachweis einer verminderten MLH1-Genexpression. Hier wird zunächst nach einer somatischen BRAF-Mutation gesucht, die zu einer Hypermethylierung des MLH1-Promoters und dadurch bedingtem Expressionsverlust führt. Das $M L H 1-G e n$ ist dann funktionell abgeschaltet, aber nicht mutiert. Somatische BRAF-Mutationen finden sich in etwa $15 \%$ der sporadisch auftretenden CRC.

Die weitere genetische Diagnostik bezieht sich auf eine Reihe seltenerer hereditärer Erkrankungen im Gastrointestinaltrakt (Tab. 3), die sich teilweise phänotypisch kaum vom Lynch-Syndrom unterscheiden. Bei der familiären juvenilen Polyposis liegt eine autosomal-dominant vererbte Mutation im SMAD4-Gen vor. Im Falle eines Mutationsnachweises wird im Sinne eines molekularen Screenings nach weiteren Genträgern in der Familie des Patienten gesucht - dies auch vor dem Hintergrund, dass Patienten mit hereditärem CRC bzw. Genträger an einer definierten Vorsorge teilnehmen sollten. Dazu gehört unter anderem eine jährliche Koloskopie ab dem 20.-25. Lebensjahr (Tab. 4).

Das beim Lynch-Syndrom obligate Vorliegen einer MSI hat auch für Patienten mit CRC im Stadium UICC II/III eine klinische Relevanz. In diesem Stadium ist postoperativ zu entscheiden, ob eine adjuvante Chemotherapie erfolgen sollte. Bei MSI hat der Patient ein niedriges Rezidivrisiko und sollte bei fehlendem 


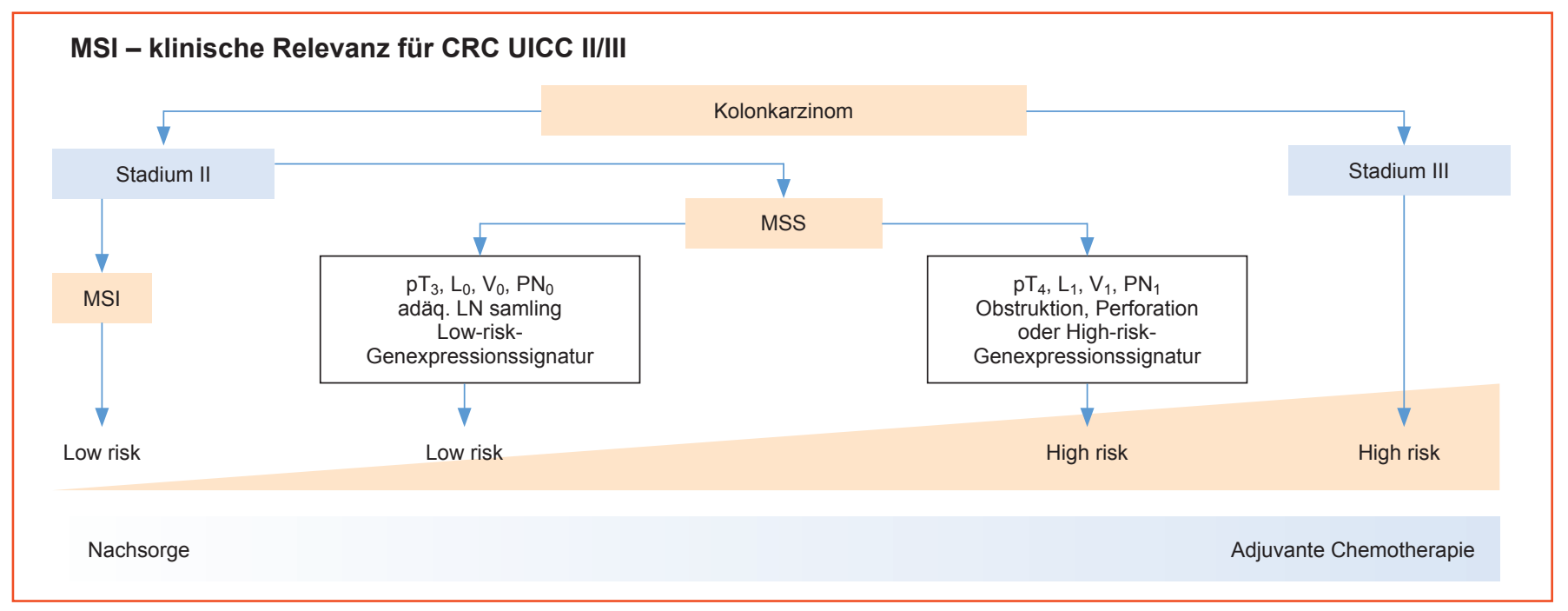

Abb. 11. Klinische Relevanz der Analyse auf MSI. MSS = Mikrosatellitenstabilität.

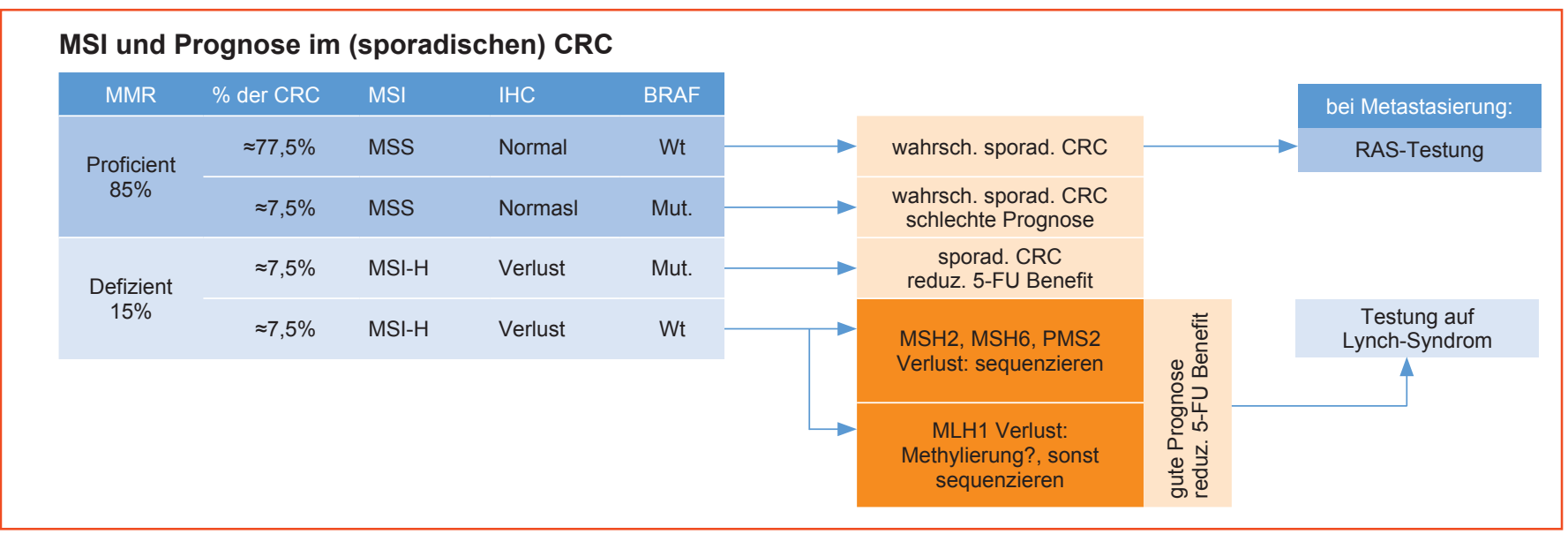

Abb. 12. Molekulargenetik und Prognose beim CRC (modifiziert nach [43]).

Nachweis einer Lymphknotenmetastasierung auf eine adjuvante Chemotherapie verzichten. Bei Mikrosatellitenstabilität erfolgt die Risikobeurteilung anhand von weiteren molekulargenetischen Befunden bzw. Surrogatparametern (Abb. 11).

In der metastasierten Situation ergeben sich für das Mikrosatelliten-instabile CRC durch die Expression einer Vielzahl von mutationsassoziierten Neoantigenen zusätzliche therapeutische Optionen [40]. So werden bei einer Therapie mit einem Checkpoint-Inhibitor wie Pembrolizumab T-Zellen aktiviert, welche diese Neoantigene erkennen können. Der Nachweis einer MSI korreliert deshalb mit einem besseren Therapieansprechen auf Pembrolizumab, das derzeit in großen klinischen Studien untersucht wird.

MMR-Defekte können ein Indikator für das Vorliegen hereditärer CRCs sein [42]. Unter Berücksichtigung der Ergebnisse zur MSI sowie der immunhistochemischen und der BRAF-Mutationsanalyse können daraus prognostische Aussagen abgeleitet werden (Abb. 12). Insbesondere Patienten, die vor dem 50. Lebensjahr an einem CRC erkranken, sollten grundsätzlich immun- histochemisch und durch Bestimmung der MSI auf eine mögliche erbliche Belastung für CRC untersucht werden, dies ist vor dem Hintergrund sinkender Kosten molekularer Diagnostik prinzipiell aber auch für ältere Patienten bei begründetem Verdacht zunehmend vertretbar.

\section{Rechtliche und ethische Fragen - Probleme des Gendiagnostikgesetzes im ärztlichen Alltag}

\section{Referent: Matthias Stroth, Berlin}

Das GenDG [43] wirft im onkologischen Bereich eine Reihe von praktischen Fragen auf, etwa zur Anwendbarkeit des Gesetzes auf somatische Mutationen, zur rechtlichen Bewertung von diagnostischen Untersuchungen mit prädiktiver Komponente sowie zum Umgang mit genetischen Informationen. Der Zweck des Gesetzes $(\$ 1)$ besteht darin, die rechtlichen Voraussetzungen für eine genetische Untersuchung zu regeln, eine Benachteiligung 


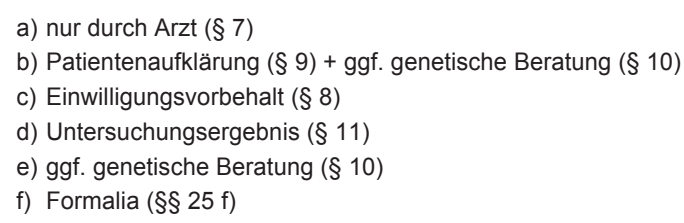

Abb. 13. Auflagen für genetische Untersuchungen im GenDG.

von Menschen aufgrund diagnostizierter genetischer Merkmale $\mathrm{zu}$ verhindern und den Schutz des Patienten auf informelle Selbstbestimmung zu wahren. Für genetische Untersuchungen entsprechend $₫ 3$ des GenDG müssen bestimmte Formalien (Abb. 13) eingehalten werden.

\section{Anwendbarkeit des GenDG auf somatische Mutationen}

Im Hinblick auf den Nachweis somatischer Mutationen geht es zunächst um die Frage, ob es sich dabei überhaupt um eine genetische Untersuchung im Sinne des GenDG handelt. Definitionsgemäß geht es dabei um eine Analyse zur Feststellung genetischer Eigenschaften, die ererbt oder bei der Befruchtung erworben worden sind (Keimbahnmutationen) oder sich bis zum Zeitpunkt der Geburt ausgebildet haben (z.B. konstitutionelle Mosaike). Sie sind für das Individuum unveränderlich und werden vererbt. Somatische Mutationen treten dagegen erst im Lauf des Lebens auf (etwa epigenetisch, strahlenbedingt oder tumorassoziiert) und fallen somit prinzipiell nicht in den Anwendungsbereich des GenDG [44].

Im Bereich der Gynäko-Onkologie ist insbesondere der geforderte Nachweis einer BRCA-Mutation zur Therapie mit Olaparib beim rezidivierten serösen Ovarialkarzinom (hochgradig) auf rechtliche Fragen im Zusammenhang mit den GenDG zu hinterfragen. Die Europäische EMA-Zulassung ermöglicht es, sowohl den Nachweis einer Keimbahnmutation als auch den einer somatischen Mutation im Tumorgewebe für die Indikationsstellung heranzuziehen. Ist eine Keimbahnmutation nachgewiesen, ist zweifelsfrei das GenDG anzuwenden. Wird dagegen lediglich eine somatische Neumutation im Tumor nachgewiesen, lässt diese keine sicheren Rückschlüsse auf eine eventuell. vorhandene Keimbahnmutation $\mathrm{zu}$, und dementsprechend findet hier das GenDG grundsätzlich keine Anwendung, es sei denn, ein zusätzlicher Bluttest weist auch eine Keimbahnmutation nach. In Deutschland wird auf eine solche ergänzende Untersuchung meist verzichtet. Denn - so eine auch von der GendiagnostikKommission (GEKO) geteilte Auffassung - entscheidend beim BRCA-Mutationsnachweis ist der Untersuchungszweck: in diesem Fall geht es primär um die Anwendbarkeit eines Arzneimittels und nicht um die Aufdeckung möglicher genetischer Belastungen.
Olaparib ${ }^{\circledR}$ beim rezidivierten seriösen Ovarialkarzinom (hochgradig)

Lösung: Patientinneninformation vor Tumortestung analog GenDG

- Aufklärung über mögliche Keimbahnbelastung

- Konsequenzen für Patienten und Familie

- BRCA: Zweitkarzinomrisiko

- Genetische Beratung anbieten

- Dokumentation

Abb. 14. Auch bei der Mutationstestung im Tumorgewebe muss vor der Testung eine Patienteninformation erfolgen, obwohl das GenDG keine Anwendung findet.

Diese pragmatische Auslegung zum Umgang mit dem $B R C A$ Mutationsnachweis ist nicht unproblematisch vor dem Hintergrund, dass bei etwa $80 \%$ der Frauen mit somatischer Mutation auch von einer BRCA-Mutation in der Keimbahn auszugehen ist. Prinzipiell dürften daher Patientinnen mit Tumor-Mutationsnachweis das gleiche Informationsbedürfnis haben wie Patientinnen mit nachgewiesener Keimbahnmutation. Der Wunsch nach Information berührt den Schutzbereich des GenDG, auch wenn dessen Anwendungsbereich bei somatischen Mutationen aus oben aufgezeigten formalen Gründen nicht betroffen ist. Die Lösung besteht darin, diese Patientinnen bereits vor der anstehenden Testung im Tumorgewebe entsprechend den Vorgaben des GenDG aufzuklären - auch bezüglich des erhöhten Risikos für Zweitkarzinome wie etwa Mammakarzinome - und bei Bedarf auch genetisch zu beraten (Abb. 14).

Hilfreich für die Informationsvermittlung im Vorfeld einer BRCA-Testung im Tumorgewebe ist eine DGHO-Dokumentvorlage (Abb. 15) zur Aufklärung und Einwilligungserklärung von Patientinnen mit Ovarialkarzinom, die aus dem Internet bezogen werden kann [45]. Wird mit solchen Formblättern gearbeitet, findet das Gespräch auf einer rechtlich sicheren Grundlage statt.

\section{Diagnostische Untersuchung mit prädiktivem Element}

Genetische Untersuchungen können entweder einen prädiktiven Zweck erfüllen oder aus diagnostischen Gründen durchgeführt werden. Der Nachweis einer BRCA-Mutation kann jedoch sowohl von prädiktiver Bedeutung sein (zur Abschätzung des Malignomrisikos bei tumorfreien Patientinnen) als auch von diagnostischem Wert sein, nämlich bei einer bereits an Krebs erkrankten Patientin. Letztere haben zusätzlich ein erhöhtes Zweitkarzinomrisiko, so dass bei ihnen der BRCA-Test als «diagnostische Untersuchung mit prädiktivem Element» prädiktiv im Hinblick auf ein mögliches künftiges Zweitkarzinom - erfolgt, wobei dieses Konstrukt nicht explizit im GenDG geregelt ist.

Die Unterteilung in diagnostische Untersuchungen (GenDG $\$ 3 \mathrm{Nr} .7$ ) und prädiktive Untersuchungen (GenDG $\$ 3 \mathrm{Nr} .8$ ) ist relevant, weil dafür unterschiedliche formelle Voraussetzungen 
Abb. 15. Auszug aus der DGHO-Dokumentationsvorlage zur BRCA-Testung im Tumorgewebe (das Formular wurde von Dr. Matthias Stroth, Berlin, und Dr. Simone Heidemann, Kiel, erarbeitet).
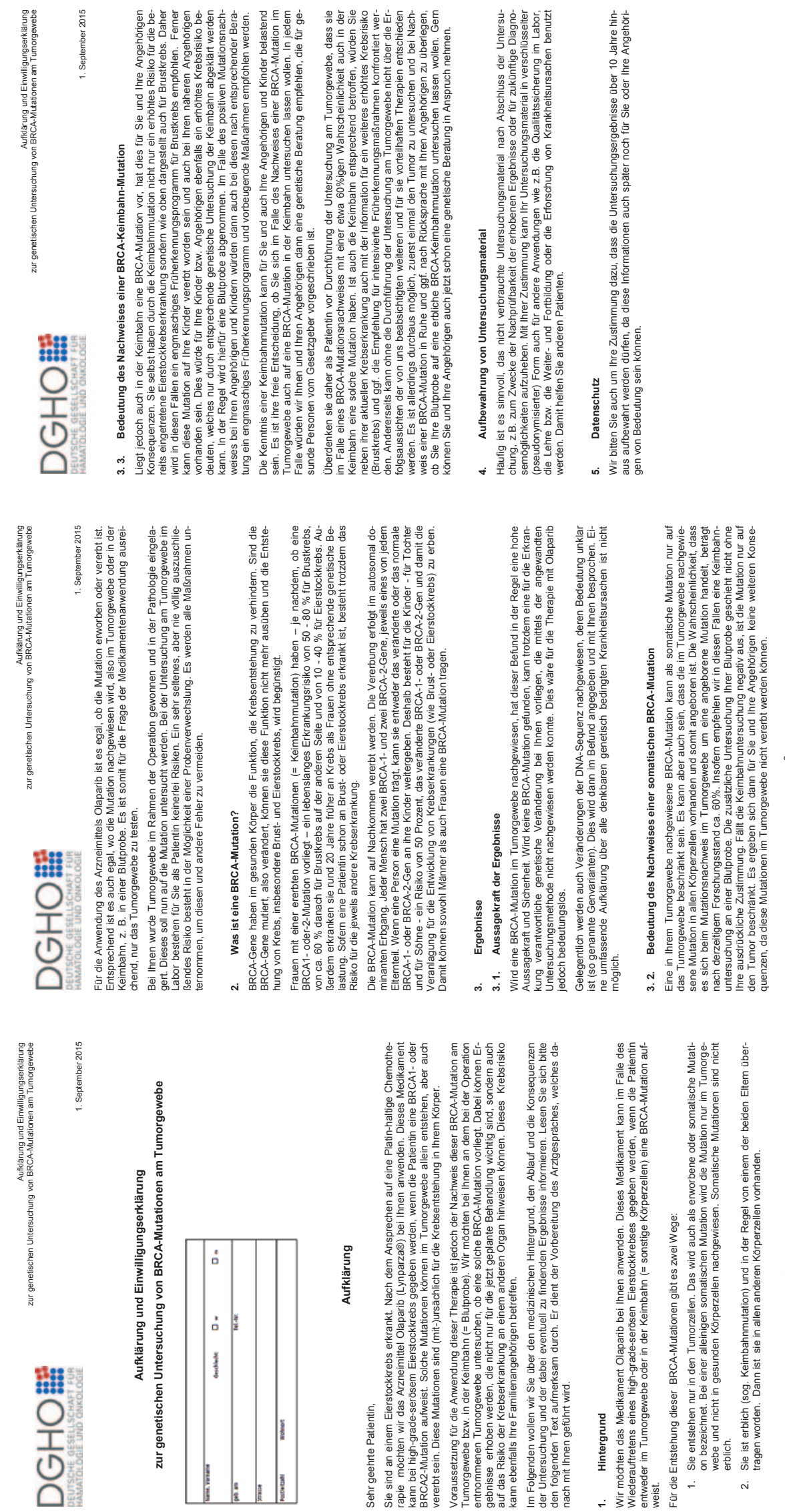
Tab. 5. Rechtliche Einordnung der BRCA-Mutationstestung (modifiziert nach [45])

\begin{tabular}{|c|c|c|c|}
\hline \multirow[t]{2}{*}{ BRCA-1/2-Mutationstestung } & \multicolumn{2}{|l|}{ Erkrankte Patientin } & \multirow{2}{*}{$\frac{\text { Gesunde Patientin }}{\text { Keimbahn }}$} \\
\hline & Tumorgewebe & Keimbahn & \\
\hline Mutationsnachweis & Tumor und Keimbahn & Keimbahn & Keimbahn \\
\hline GenDG anwendbar? & nein & $\begin{array}{l}\S 3 \mathrm{Nr} .7 \text { GenDG: diagnostisch } \\
\text { mit prädiktivem Element }\end{array}$ & $\begin{array}{l}\S 3 \mathrm{Nr} .8 \text { GenDG: prädiktive } \\
\text { Untersuchung }\end{array}$ \\
\hline Aufklärung & $\begin{array}{l}\$ \$ 8,9 \text { GenDG analog } \\
\text { familiäre Belastung } \\
\text { Zweitkarzinomrisiko }\end{array}$ & $\begin{array}{l}\$ \$ 8,9 \text { GenDG } \\
\text { familiäre Belastung } \\
\text { Zweitkarzinomrisiko }\end{array}$ & $\begin{array}{l}\S \S 8,9 \text { GenDG } \\
\text { familiäre Belastung } \\
\text { Karzinomrisiko }\end{array}$ \\
\hline Genetische Beratung & anbieten $^{*}$ & & \\
\hline Datenschutz & $\$ \$ 11,12$ GenDG analog & $\$ \$ 11,12$ GenDG analog & $\$ \$ 11,12$ GenDG analog \\
\hline Form & $\begin{array}{l}\text { mündlich (Schriftform } \\
\text { empfohlen) }\end{array}$ & $\S \S 8,9$ GenDG schriftlich & $\S \S 8,9$ GenDG schriftlich \\
\hline $\begin{array}{l}\text { Qualifikationsvoraussetzung zur } \\
\text { Veranlassung }\end{array}$ & jeder Arzt & $\begin{array}{l}\S 7 \text { Abs. } 1 \text { Alt. } 1 \text { GenDG: } \\
\text { jeder Arzt }\end{array}$ & $\begin{array}{l}\S 7 \text { Abs. } 1 \text { Alt. } 2 \text { GenDG: } \\
\text { - Facharzt für Humangenetik } \\
\text { - Zusatzbezeichnung «Medizinische Genetik» } \\
\text { - Qualifikation nach GenDG }\end{array}$ \\
\hline
\end{tabular}

*Bei Vorhandensein der Qualifikation zur fachgebundenen genetischen Beratung kann die genetische Beratung vom behandelnden Frauenarzt selbst durchgeführt werden.

zu erfüllen sind. So sieht lediglich die prädiktive Untersuchung eine vorhergehende genetische Beratung vor. Die dann obligat vorgeschaltete genetische Beratung führt jedoch in aller Regel zu einem gewissen Zeitverzug, der unter dem praktischen Gesichtspunkt einer zeitnahen Therapie nicht vom Arzt und sicher noch weniger von der Patientin gewünscht wird. Außerdem müssen Ärzte, die prädiktive genetische Untersuchungen vornehmen, dafür nach $₫ 7$ Abs. I Alt. 2 GenDG qualifiziert sein.

Für die Einordung des BRCA-Tests als rein diagnostische Untersuchung spricht, dass für eine solche Untersuchung keine spezielle Arztqualifikation nach GenDG nötig ist und sich die Patientin lediglich mit der Abklärung des Erstkarzinoms befassen muss. Dies impliziert andererseits, dass eine gegebenenfalls bezüglich des Zweitkarzinoms nicht vorab informierte Patientin bei einem positiven BRCA-Mutationsnachweis unvorbereitet mit dem Zweitkarzinomrisiko konfrontiert wird.

Nach Abwägung dieser Pro- und Contra-Überlegungen sollte ein pragmatischer Weg gewählt werden (Abb. 16): Der Nachweis wird im Rahmen einer diagnostischen Untersuchung geführt, aber die Patientin erhält vor der Untersuchung einer umfassende Aufklärung, insbesondere in Bezug auf das Risiko für Zweitkarzinome wie bei der prädiktiven Untersuchung. Ausführliche Erläuterungen dazu enthält der Artikel «Patientenaufklärung vor BRCA-Mutationsanalyse», der in der Zeitschrift Frauenarzt erschienen ist [46]. In dem Text werden die Aufklärungs- und Beratungspflichten beim Nachweis von Keimbahn- und somatischen Mutationen dargestellt (Auszug siehe Tab. 5) sowie forensische Risiken aufgezeigt.

\section{Genetische Untersuchung}

- Diagnostische Untersuchung mit prädiktivem Element

$\rightarrow$ nicht geregelt im GenDG

- Lösung: Wie diagnostische Untersuchung, aber

$\rightarrow$ umfassende Patientinnenaufklärung im Vorfeld

$\rightarrow$ insbesondere Zweitkarzinomrisiko darstellen

$\rightarrow$ informed consent herstellen

$\rightarrow$ Dokumentation

Abb. 16. Zum Umgang mit diagnostischen Untersuchungen mit prädiktivem Element.

\section{Umgang mit genetischen Informationen}

Beim Umgang mit sensiblen Informationen im Zusammenhang mit der Patientenaufklärung (GenDG $\$ 9$ ), der genetischen Beratung (GenDG \$10) und der Erläuterung der Untersuchungsergebnisse (GenDG $\$ 11$ ) können rechtliche Probleme auftreten, und zwar aus juristischer Sicht nicht nur in Form einer fehlerhaften genetischen Beratung, sondern auch durch eine ungewollte Konfrontation mit belastenden genetischen Informationen oder durch Verletzung der ärztlichen Schweigepflicht.

Eine ungewollte Ergebnismitteilung verletzt das Recht des Patienten auf informelle Selbstbestimmung, das als Schutzzweck im GenDG verankert ist. Der genetisch beratende Arzt hat das «Recht auf Nichtwissen» zu akzeptieren und kann andernfalls auf 
Schadenersatz verklagt werden. Das informelle Selbstbestimmungsrecht schützt aber nach einem Urteil des Bundesgerichtshofs (BGH, 20.05.2014, VI ZR 381/13) nicht vor Informationen zu möglichen Erkrankungsrisiken von Dritten (z.B. leibliche Kinder). In dem vor dem BGH verhandelten Fall wurde etwa die Schmerzensgeldklage einer Frau abgewiesen, die von einem Arzt ungewollt über die Chorea-Huntington-Erkrankung ihres ehemaligen Ehemanns und das mögliche Erkrankungsrisiko der gemeinsamen Kinder informiert worden war.

Um eine ungewollte Ergebnismitteilung zu vermeiden, sollte vor der Untersuchung schriftlich dokumentiert werden, über welche möglichen Konsequenzen und Risiken aufgeklärt wurde und inwieweit die Patientin insofern informiert werden möchte. Für eine Patientin mit BRCA-Mutationstestung in der Keimbahn bedeutet das: Vorab-Info bezüglich des erhöhten Karzinomrisikos (Erst- bzw. Zweitkarzinomrisiko für Eierstock- und Brustkrebs) sowie mögliche familiäre Belastungen bei positiver BRCA-Mutationsanalyse.

Werden Familienangehörige eines genetisch untersuchten $\mathrm{Pa}$ tienten ohne dessen Einverständnis über die Untersuchungsergebnisse informiert, hat der Arzt seine Schweigepflicht verletzt. So verurteilte etwa das Oberlandesgericht München einen Arzt zu einer Schadenersatzzahlung, der eine schwerwiegende neurologische Diagnose eines Patienten ohne dessen Einverständnis an dessen Ehefrau übermittelt hatte (OLG München, 04.02.2010; 1 U 4650/08). Patienten sind im Falle einer nachgewiesenen genetischen Belastung nach entsprechender ärztlicher Beratung gemäß $\$ 10$ Abs. 3 S. 4 GenDG selber gehalten, ihren möglicherweise ebenfalls betroffenen Familienangehörigen eine genetische Beratung zu empfehlen. Ein Arzt hat nach aktueller Rechtsprechung ohne Einwilligung des Patienten nur bei akuter Lebensgefahr für gegebenenfalls betroffene Dritte ein Mitteilungsrecht gegenüber diesen. Es bleibt deshalb festzuhalten, dass medizinische Befunde - und hier insbesondere sensible genetische Informationen - nur mit ausdrücklicher Zustimmung des Patienten an Dritte weiter gegeben werden dürfen.

\section{Rechtliche und ethische Fragen - ethische Herausforderungen bei der molekulargenetischen Diagnostik krebsassoziierter Gene}

\section{Referentin: Christiane Woopen, Köln}

Bei ethischen Fragestellungen geht es zuvorderst um die Legitimität der verfolgten Zwecke und die Vertretbarkeit der eingesetzten Mittel. Diagnostische, prognostische und prädiktive genetische Untersuchungen haben bei vorhandener Einwilligung zweifelsfrei einen legitimen Zweck, da sie dem Patienten wichtige Informationen bis hin $\mathrm{zu}$ Therapieentscheidungen liefern. Ethisch problematisch können solche Untersuchungen sein, wenn sie bei einwilligungsunfähigen Patienten vorgenommen werden.
Ethisch zu hinterfragen sind die eingesetzten Mittel, mit denen die genetischen Informationen erlangt werden. Das NGS etwa kann prinzipiell große Datensätze liefern, die weit mehr beinhalten als die angefragte Information. Bei sogenannten Direct-ToConsumer(DTC)-Tests, die in der Regel kommerziell vertrieben werden, sind Aufklärung des Einsenders und genetische Beratung oft unzureichend [47]. Auch systemmedizinische Ansätze («bigdata») müssen unter ethischen Gesichtspunkten differenziert betrachtet werden.

Ethische relevante Herausforderungen stellen sich unter verschiedenen Aspekten:

\section{Krankheits- und Gesundheitsverständnis}

«Krebs ist eine Genomkrankheit. Er entsteht durch Mutationen im Erbgut» (Zitat Todd R. Golub, Broad Institute of MIT and Harvard), heißt es oft aus molekulargenetischer Sicht. Philosophisch gesehen ist die Mutation jedoch nicht zwangsläufig die Krebsursache, sondern auch andere, womöglich nichtmolekulargenetische Ursachen könnten die Mutationen auslösen und in der Folge zu Krebs führen. An dieser Stelle treffen biologistische Vorstellungen und ein ganzheitliches Menschenbild aufeinander. Letzteres könnte implizieren, dass eine Mutation lediglich die biologische Manifestation einer anderweitig zu suchenden Krebsursache ist.

\section{Selbstbestimmung}

Die Selbstbestimmung setzt sich aus sieben Begriffskomponenten zusammen (Abb. 17), die sich den drei Clustern Wissen (Kompetenz, Informiertheit), Freiheit (Wahlmöglichkeit, Werte, Freiwilligkeit) und Realisierung (Handlung, Willensbildung) zuordnen lassen. Um selbstbestimmt zu handeln, muss man Informationen erlangen, diese verstehen und in ihrer Relevanz bewerten können. Entscheidungen setzen voraus, dass es eine Wissensgrundlage sowie eine Wahlmöglichkeit gibt. Zu berücksichtigen sind auch individuelle Präferenzen sowie die Freiwilligkeit, die z.B. durch sozialen Druck - etwa in Hinblick auf die Inanspruchnahme einer genetischen Pränataldiagnostik - gefährdet sein kann. Für die Willensbildung spielt die Aufklärung und Beratung durch den Arzt eine wichtige Rolle.

Unter dem Aspekt der Selbstbestimmung sind freiverkäufliche DTC-Tests insofern problematisch, da aus den gewonnenen Genprofilen je nach Umfang der gewählten Services eine große Vielfalt gesundheitlicher Erkrankungs- und Risikokonstellationen untersucht und daraus unterschiedliche Konsequenzen (Sport, Ernährung, Therapie usw.) abgeleitet werden. Eine dazugehörige ärztliche Beratung in einem persönlichen Gespräch erfolgt meist nicht. Die klassische Arzt-Patient-Beziehung findet hier nicht mehr statt. Je nach Befund kann der Kunde in eine erhebliche Lebenskrise geraten. 


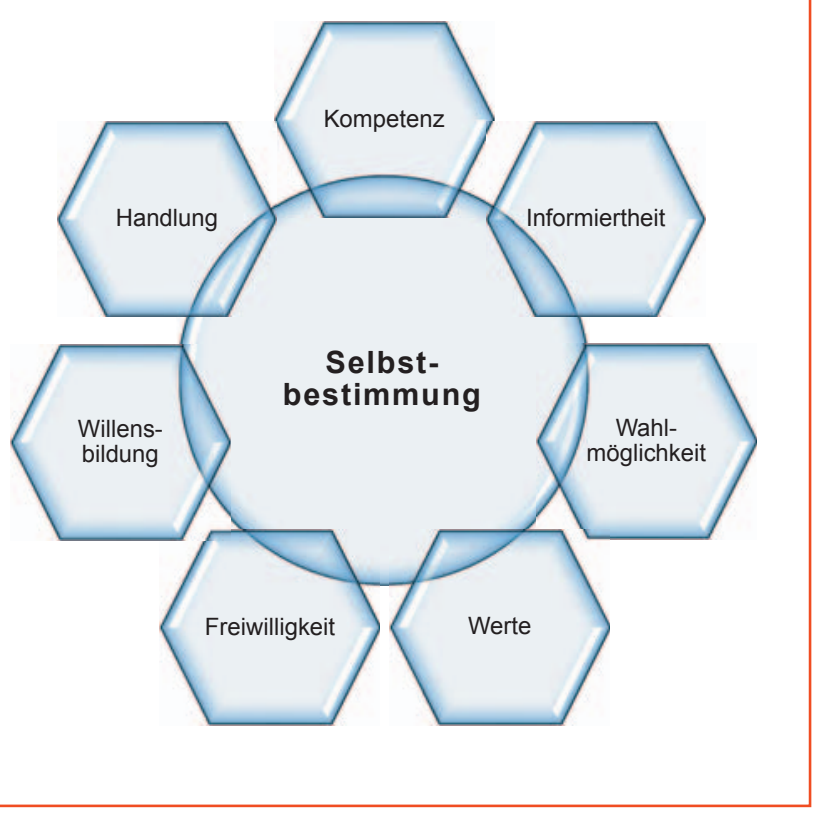

Abb. 17. Komponenten der Selbstbestimmung.

\section{Datenschutz, Privacy}

Datenschutz und Schutz der Privatsphäre sind in Zeiten, in denen medizinische Daten, Daten aus dem Gesundheitswesen, Lifestyle-Daten, Versicherungsdaten, durch Patienten generierte Daten und Daten aus sozialen Netzwerken zu einem großen «Big data»-Paket zusammengeschnürt werden, ein besonders sensibler Bereich. Im Sinne einer ganzheitlichen Betrachtung des Menschen, die sich nicht nur auf die Beurteilung von Laborwerten beschränkt, wäre eine solch umfassende Datensammlung an sich begrüßenswert. Wenn aber nicht klar ist, wer Zugriff auf die Datenbanken hat, wie und mit welcher Intention die Auswertung der Rohdaten erfolgt und nach welchen Prinzipen daraus Handlungsempfehlungen abgeleitet werden, ist ein ausreichender Datenschutz nicht gesichert. Auch die neue EU-Datenschutz-Grundverordnung ist noch nicht auf die spezifischen Anforderungen durch «Big data»Pakete in der Medizin abgestimmt, sondern knüpft an die klassischen Datenschutz-Prinzipien von Zweckbindung, Datensparsamkeit usw. an.

\section{Eltern-Kind-Verhältnis}

Die Frage nach ethischem Handeln stellt sich im Eltern-KindVerhältnis, z.B. wenn im Rahmen der Präimplantations- oder Pränataldiagnostik nach Dispositionsgenen wie einer BRCA-Mutationen gesucht wird, wie dies in einigen Ländern bereits stattfindet. Darüber hinaus stellt sich die Frage, ob nicht alternativ fehlerhafte Erbanlagen mittels CRISPR-Cas9-Methode aus dem Erbgut ausgeschnitten werden könnten. Die neuen Entwicklun- gen auf diesem Gebiet rufen derzeit einen kontroversen ethischen Diskurs über Manipulationen an der menschlichen Keimbahn hervor.

Selbst die nichtinvasive Gesamt-Genom-Sequenzierung eines menschlichen Fetus ist bereits vor einigen Jahren gelungen [48]. Die Gesellschaft muss entscheiden, ob solche weit reichenden genetischen Untersuchungen bei Ungeborenen gewollt sind. Aus ethischer Sicht ist es nach meiner Überzeugung sehr zweifelhaft, ob Eltern das Recht haben, die komplette genetische Ausstattung ihrer Nachkommen zu kennen.

\section{Gerechtigkeit und Solidarität}

Im Zusammenhang mit der Modernisierung und Digitalisierung der Medizin finden sich vier Entwicklungen, die Fragen zu Gerechtigkeit und Solidarität aufwerfen: Das Umdenken von einer krankheits- hin zu einer gesundheitsorientierten Medizin, die Verlagerung des Schwerpunkts weg von der Therapie hin zur Prävention, die Ausweitung der Gesundheitsberatung zur Lebensberatung und ein neues Rollenverständnis, demgemäß der Patient zum Kunden wird.

Laut einer Trendforschungsstudie zur personalisierten Medizin der Zukunft [49] werden sich möglicherweise künftig Menschen ihr individuelles Gesundheitsnetz per App zusammenstellen und digital Empfehlungen bezüglich Gesundheitsrisiken, möglichen Therapien und Lebensführung bis hin zur Urlaubsgestaltung erhalten. Patienten werden "health seeker», die ihre persönlichen Gesundheitsdaten zur Optimierung ihres Wohlbefindens nutzen wollen. Menschen suchen Anbieter, die Daten aus verschiedensten Quellen für Beratung und Therapie berücksichtigen. Die Informationsmenge wird so komplex, dass sie ohne Unterstützung nicht mehr zu bewältigen ist. Im Gesundheitswesen wird es wohl Bereiche geben, die von digitalen Assistenten übernommen werden.

Auf dem Weg von der solidarischen Gesundheitsversorgung zur individuellen Verantwortungsübernahme wird sich das Verständnis von Solidarität ändern.

Wer seine Daten angesichts verhaltensbasierter Versicherungsmodelle nicht weitergeben will, geeignete Daten aufgrund von Krankheit, Behinderung oder schwierigen Lebensverhältnissen nicht produzieren kann oder primär datengestützte Gesundheitskonzepte (Prämienmodelle, Bonuspunkte) ablehnt, fällt dann aus dem Solidarsystem heraus. Solidarität kann aber auch als moralische Pflicht zu Diagnostik und gesunder Lebensführung verstanden werden (Abb. 18), etwa als moralische Pflicht zur BRCA-Mutationstestung bei Verdacht auf familiäre Krebsdisposition.

Vor dem Hintergrund dieser Überlegungen hat der Deutsche Ethikrat 2013 in einer Stellungnahme zur Zukunft der genetischen Diagnostik eine Reihe von Empfehlungen ausgesprochen und fordert unter anderem [47]:

- Ablehnung eines einseitig genetisch-biologistischen Krankheitsbildes, 


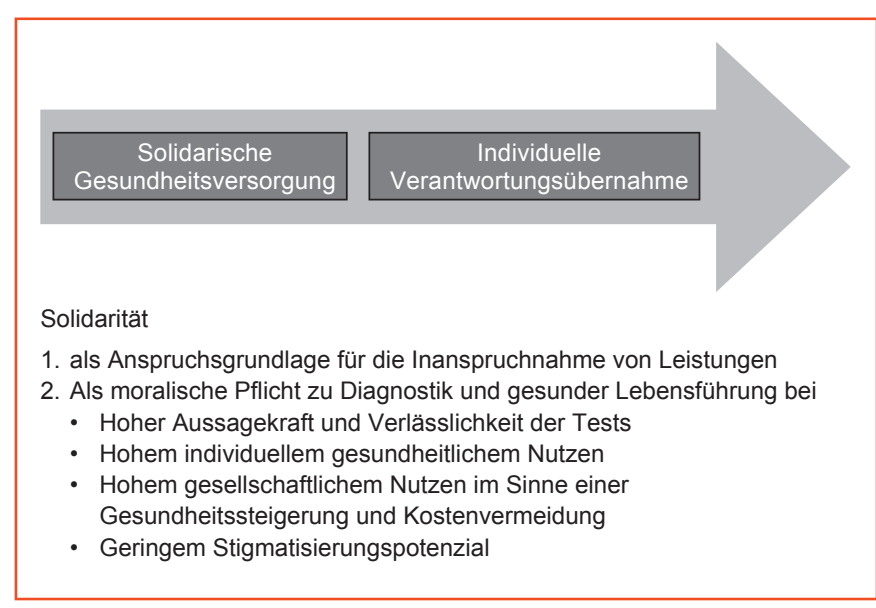

Abb. 18. Solidarität und individuelle Verantwortungsübernahme.

- öffentlich getragene Informationsplattform $\mathrm{zu}$ verfügbaren Gentests,

- Prüfung des Berufsbilds eines genetischen Beraters,

- Bedeutung des persönlichen Gesprächs im GenDG stärken,

- Aufklärung und Beratung über Typen möglicher Ergebnisse ermöglichen (Krankheitsgruppen, Schweregrad, Behandelbarkeit, Wahrscheinlichkeit und Zeitpunkt der Manifestation),

- Beschränkung der Datenerhebung bei nicht einwilligungsfähigen Personen,

- kein eigenständiges Recht des Arztes auf Information von Verwandten eines Patienten,

- Kostenerstattung von sogenannten «companion diagnostics» sowie

- Förderung von Patienten- und Verbraucherschutz bei DTCTests auf europäischer Ebene.

\section{Rechtliche und ethische Fragen - molekulare Diagnostik: Herausforderungen im «Dreiecksverhältnis» zwischen Arzt, Patient und Angehörigen}

\section{Referent: Karsten Engelke, Berlin}

Nicht alle Gensequenzierungen und molekularen Untersuchungen fallen in den Anwendungsbereich des GenDG. Abgedeckt werden lediglich Bereiche der medizinischen Versorgung (Untersuchungen zu medizinischen Zwecken, womit die Feststellung ererbter oder vorgeburtlich erworbener genetischer Eigenschaften gemeint ist), der Abstammungsklärung und des Arbeitslebens. Gensequenzierungen zu anderen medizinischen Zwecken, etwa der Ernährungs- oder Lifestyle-Beratung, unterliegen nicht den Vorschriften des GenDG und können z.B. ohne die im GenDG verankerten Beratungspflichten kommerziell angeboten werden. Hier besteht jedoch eine rechtliche Grauzone.
Bei molekularen Untersuchungen (zu denen außer Gensequenzierungen etwa auch zytogenetische Untersuchungen gehören), die unter das GenDG fallen, können in der Kommunikation zwischen Arzt, Patient und Angehörigen weitere Rechtsbereiche tangiert sein. Der Rechtsrahmen umfasst außer dem GenDG insbesondere das im Bürgerlichen Gesetzbuch verankerte Haftungsrecht und das im Strafgesetzbuch verortete Strafrecht.

\section{Haftungsrechtliche Fragen}

Das Haftungsrecht geht davon aus, dass zwischen Arzt und Patient ein Behandlungsvertrag besteht. Es dient dem Schutz allgemeiner Rechtsgüter (Leben, körperliche Unversehrtheit, allgemeines Persönlichkeitsrecht einschließlich personenbezogener Daten). Einer Haftung geht eine Verhaltenspflichtverletzung voraus, etwa das Nichteinhalten von Vereinbarungen oder die Nichtbeachtung von Sorgfaltsstandards. Letztere orientieren sich häufig an Leitlinien, Behandlungsempfehlungen oder fachkompetenten Stellungnahmen. Die Rechtsfolge bei einer nachweislichen Verhaltenspflichtverletzung ist der Schadensersatz. Bei der Festsetzung eines Schadensersatzes sind Fragen der Kausalität (Ist der Schaden eindeutig auf ein Fehlverhalten zurückzuführen?), der Adäquanz (Steht der eingetretene Schaden in einem adäquaten Verhältnis zum auslösenden Moment?) und des Zurechnungszusammenhanges (Welche Folgen sind dem Schadensverursacher zuzurechnen und welche sind womöglich schicksalhaft bzw. ein allgemeines Lebensrisiko?) zu beachten.

\section{Rechtsvorgaben im GenDG}

Alle Begriffsdefinitionen im GenDG sind an die gesetzlichen Schutzzwecke geknüpft, so dass zunächst geprüft werden muss, ob die ins Auge gefasste genetische Untersuchung zu schützende Interessen eines Menschen berührt und somit in den Anwendungsbereich des GenDG fällt. Der Anwendungsbereich umfasst im medizinischen Bereich nur diagnostische und prädiktive genetische Untersuchungen und gilt nur für ererbte oder vorgeburtlich erworbene Mutationen. Liegt ein solcher Fall vor, müssen die Vorgaben des Gesetzes, z.B. für die Gewinnung, Bearbeitung und Verwendung von Blut- oder Gewebeproben, eingehalten werden. Gegenüber dem Patienten bestehen umfangreiche Aufklärungs-, Beratungs- und Dokumentationspflichten. Wird dagegen verstoßen, greifen die im GenDG fixierten Straf- und Bußgeldvorschriften. Bislang gibt es keine rechtlich belastbare Verknüpfung des GenDG mit dem Haftungsrecht, da in dieser Frage formal noch nicht entschieden worden ist. Bei Verletzung des GenDG müssen jedoch prinzipiell auch haftungsrechtliche Konsequenzen in Betracht gezogen werden sowie ein mögliche berufsrechtliche Relevanz. 


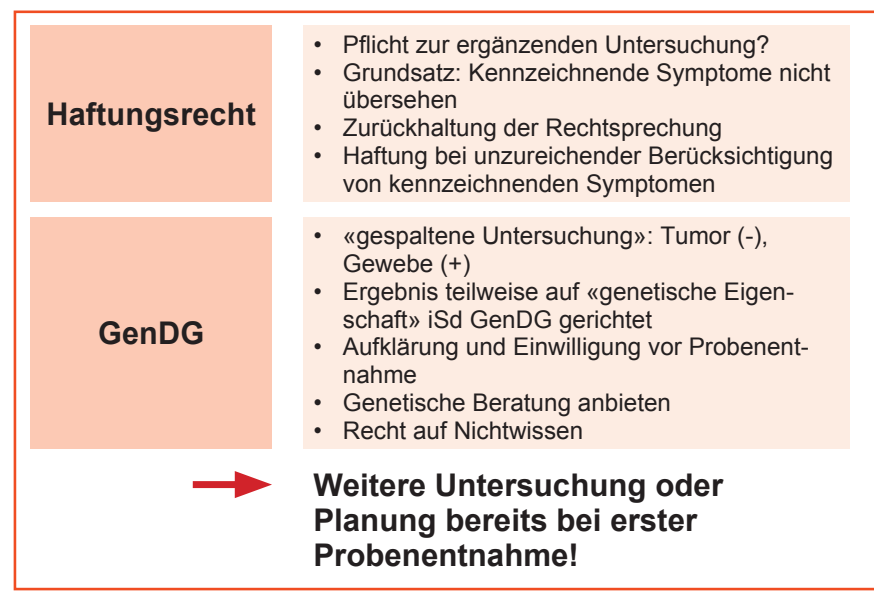

Abb. 19. Rechtsrahmen für ergänzende Untersuchungen zur Abklärung somatischer Mutationen.

\section{Strafrechtliche Fragen}

Strafrechtlich geahndete Vergehen führen regelmäßig auch zur Haftung und sind mit einem Ermittlungsverfahren verbunden. Vielfach finden vor Ort Durchsuchungen mit der Beschlagnahmung von Akten statt. Auch wenn das Verfahren sodann eingestellt werden sollte, sind die Ermittlungsmaßnahmen öffentlichkeitswirksam und häufig geschäftsschädigend. Ein großer Teil der Ermittlungsverfahren wird eingestellt, andernfalls kann bei Verurteilung ein breites Spektrum an Strafen (Haft- oder Geldstrafe, Berufsverbot) verhängt werden.

\section{Mögliche Problemkonstellationen}

Frage: Es liegt ein Sequenzierungsergebnis aus Tumorgewebe vor, das mehr Gene umfasst, als es die Indikationsstellung erfordert wie ist mit den Daten umzugehen?

Hier sind zunächst haftungsrechtliche Entscheidungen zu berücksichtigen. Nach einem Urteil des Bundesgerichtshofs darf ein Arzt für ihn erkennbare Befunde dem Patienten nicht vorenthalten; so muss etwa ein Anästhesist bei Verdacht auf einen Lungentumor in der Bildgebung weiterführende Untersuchungen veranlassen. Fällt eine Sequenzierung in den Bereich des GenDG, hätte im Übrigen der Patient schon vor der Probenentnahme auf mögliche weitere relevante Untersuchungsergebnisse hingewiesen werden müssen und diese wären ihm dann auch im Rahmen der Befundung mitzuteilen. Da es bei einer tumorgeweblichen genetischen Untersuchung jedoch nicht primär um den Nachweis einer Keimbahnmutation geht, ist das GenDG hier nicht anzuwenden. Es entscheidet also allein die Intention, mit der die Untersuchung durchgeführt wird (Evaluierung einer therapeutischen Option oder Nachweis einer hereditären Belastung), ob das GenDG anzuwenden ist.

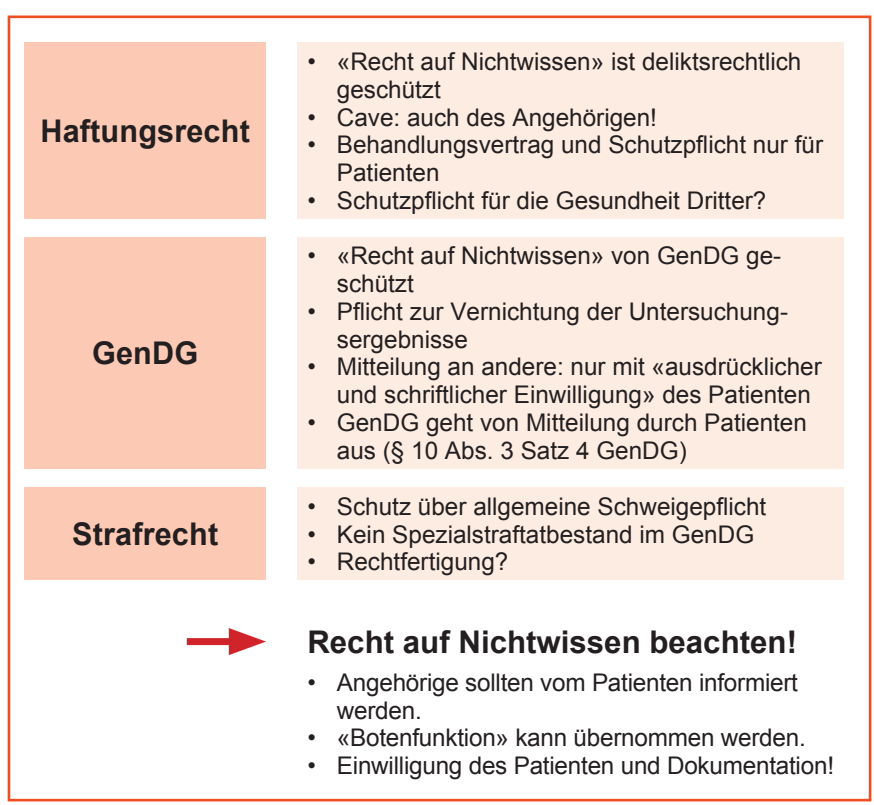

Abb. 20. Das «Recht auf Nichtwissen» ist zu akzeptieren.

Frage: Das Sequenzierungsergebnis im Tumorgewebe umfasst nur das gewünschte Gen, dieses könnte aber auch ererbt sein. Ist eine ergänzende Untersuchung auf eine Keimbahnmutation nötig?

Prinzipiell sind Ärzte bei unzureichender Berücksichtigung von kennzeichnenden Krankheitssymptomen in der Haftpflicht (Abb. 19) - wobei hier die Rechtsprechung zurückhaltend agiert vor dem Hintergrund, dass kennzeichnende Symptome recht unspezifisch sein können. Ob der Befund aus einer Tumormutationsanalyse als «kennzeichnendes Symptom» für eine ererbte $\mathrm{Mu}$ tation $\mathrm{zu}$ werten ist und somit eine weiterführende Abklärung geboten ist, ist fraglich, zumal der Begriff «Symptom» nicht ohne weiteres auf die Molekulardiagnostik anzuwenden ist. In Bezug auf das GenDG wären in dieser Fallkonstellation zwei Untersuchungen nötig, nämlich eine erste ohne Anwendung des GenDG für den Mutationsnachweis im Tumorgewebe und eine weitere unter Berücksichtigung der Auflagen des GenDG für den Nachweis der Erblichkeit. Erscheinen schon im Vorfeld beide Untersuchungen sinnvoll - etwa bei einem anstehenden BRCA-Mutationsnachweis aufgrund des hohen Anteils an Keimbahnmutationen - ist es vorteilhaft, die Patienten bereits vor der ersten Probenentnahme nach den Vorgaben des GenDG zu informieren und zu beraten.

Frage: Das Sequenzierungsergebnis weist auf ein hohes Risiko für den Patienten oder seine Angehörigen hin. Wer ist diesbezüglich zu informieren?

Das deliktsrechtlich geschützte «Recht auf Nichtwissen» gilt für jeden Bürger, also gleichermaßen für Patienten wie für Angehörige (Abb. 20). Jedoch ist ein Arzt nur gegenüber seinem Patienten, mit dem er einen Behandlungsvertrag eingegangen ist, diesbezüglich in der Schutzpflicht. Gegenüber Dritten gilt die allgemeine Schweigepflicht. Das GenDG geht davon aus, dass die 
Patienten in der Regel selbst ihre Angehörigen über die Untersuchungsergebnisse in Kenntnis setzen. Ist dies nicht der Fall, muss der Arzt eine Güterabwägung vornehmen: Ist die Schweigepflicht zu wahren, oder sind die Angehörigen zu informieren, um sie vor möglichen Erkrankungen zu bewahren? Aus rechtlicher Sicht darf die Schweigepflicht nur bei akuter Lebensgefahr gebrochen werden. Da dies bei Mutationsnachweisen kaum der Fall ist, muss der Verzicht auf eine patientenseitige Information von Angehörigen akzeptiert werden. Eine «Botenfunktion» darf der Arzt nur übernehmen, wenn dies vom Patienten gewünscht ist. Dies bedarf unbedingt der sorgfältigen Dokumentation.
Frage: Ist das Aufbewahren von Proben für Bestätigungstestungen oder weitere Untersuchungen erlaubt?

Über die Gewinnung, den Umgang, die Weiterverwendung sowie die Aufbewahrung seiner Probe entscheidet allein der Patient. Sollen die Proben zum Zwecke einer späteren erneuten Untersuchung aufgehoben werden, muss der beabsichtigte Zweck benannt werden und der Patient der Aufbewahrung schriftlich zustimmen. Eine Probenaufbewahrung ohne Benennung eines neuen Untersuchungszwecks ist aufgrund der weitrechenden $\mathrm{Pa}$ tientenautonomie problematisch und sollte unterbleiben.

\section{Disclosure Statement}

Bei keinem der Autoren bestehen Interessenkonflikte.

\section{Literatur}

1 Metzker ML: Sequencing technologies - the next generation. Nat Rev Genet 2010;11:31-46.

2 McLaughlin HM: A systematic approach to the reporting of medically relevant findings from whole genome sequencing. BMC Med Genet 2014;15:134.

3 O'Rawe J: Low concordance of multiple variant-calling pipelines: practical implications for exome and genome sequencing. Genome Med 2013;5:28.

4 Yang Y, et al: Clinical whole-exome sequencing for the diagnosis of Mendelian disorders. N Engl J Med 2013; 369:1502-1511.

5 Richards S, et al: Standards and guidelines for the interpretation of sequence variants: a joint consensus recommendation of the American College of Medical Genetics and Genomics and the Association for Molecular Pathology. Genet Med 2015;17:405-423.

6 Matthijs G; et al. Guidelines for diagnostic next-generation sequencing. Eur J Hum Genet 2016;24:2-5.

7 Høberg-Vetti $\mathrm{H}$, et al: BRCA1/2 testing in newly diagnosed breast and ovarian cancer patients without prior genetic counselling: the DNA-BONus study. Eur J Hum Genet 2016;24:881-888.

8 Chapman $\mathrm{PB}$, et al: Improved survival with vemurafenib in melanoma with BRAF V600E mutation. $\mathrm{N}$ Engl J Med 2011;364:2507-2516.

9 Hyman DM, et al: Vemurafenib in multiple nonmelanoma cancers with BRAF V600 mutations. N Engl J Med 2015;373:726-736.

10 Murtaza M, et al: Non-invasive analysis of acquired resistance to cancer therapy by sequencing of plasma DNA. Nature 2013;497:108-112.

11 Khurana E, et al: Role of non-coding sequence variants in cancer. Nat Rev Genet 2016;17:93-108.

12 Beschluss des Bewertungsausschusses nach $\$ 87$ Abs. 1 Satz 1 SGB V in seiner 372. Sitzung am 11. März 2016 zur Änderung des Einheitlichen Bewertungsmaßstabes (EBM) mit Wirkung zum 1. Juli 2016.

13 Hummel M: Voraussetzungen für die molekularbiologische Diagnostik in der Pathologie. Verh Dtsch Ges Pathol 1994;78:161-165.

14 Sanger F, Nicklen S, Coulson AR: DNA sequencing with chain-terminating inhibitors. Proc Natl Acad Sci U S A 1977;74:5463-5467.

15 Ellis LW: PARP inhibitors in cancer therapy: promise, progress and puzzles. Cancer Cell 2011;19:165-167.

16 Ledermann J, et al: Olaparib maintenance therapy in platinum-sensitive relapsed ovarian cancer. N Engl J Med 2012;366:1382-1392.
17 Jänne PA, et al: AZD9291 in EGFR inhibitor-resistant non-small-cell lung cancer. N Engl J Med 2015;372: 1689-1699.

18 Sherwood JL, et al: Optimised Pre-analytical methods improve KRAS Mutation detection in circulating tumour DNA (ctDNA) from patients with non-small cell lung cancer (NSCLC). PLoS ONE 2016;11:e0150197.

19 Sausen, M., et al: Clinical implications of genomic alterations in the tumour and circulation of pancreatic cancer patients. Nat Commun 2015;6:7686.

20 Norton SE, et al: A new blood collection device minimizes cellular DNA release during sample storage and shipping when compared to a standard device. J Clin Lab Anal 2013;27:305-311.

21 Ritter J, et al: Donor CD4 T cell diversity determines virus reactivation in patients after HLA-matched allogeneic stem cell transplantation. Am J Transplant 2015;15:2170-2179.

22 Schwaederle M, et al: Impact of precision medicine in diverse cancers: a meta-analysis of phase II clinical trials. J Clin Oncol 2015;33:3817-3825.

23 Kostenko A: An integrated cost-effectiveness and outcome analysis based on multiplex lung cancer genotyping in the network genomic medicine. IASLC-Congress 2015;ORAL06.07.

24 König K, et al: Implementation of Amplicon parallel sequencing leads to improvement of diagnosis and therapy of lung cancer patients. J Thorac Oncol 2015; 10:1049-1057.

25 Shaw AT, et al: Clinical activity of crizotinib in advanced non-small cell lung cancer (NSCLC) harboring ROS1 gene rearrangement. J Clin Oncol 2012;30 (suppl):abstr 7508.

26 Van Allen EM, et al: Genomic correlates of response to CTLA-4 blockade in metastatic melanoma. Science 2015;350:207-211.

27 Rizvi NA, et al: Cancer immunology. Mutational landscape determines sensitivity to PD-1 blockade in nonsmall cell lung cancer. Science 2015;348:124-128.

28 Placke T, et al: Requirement for CDK6 in MLL-rearranged acute myeloid leukemia. Blood 2014;124:13-23.

29 Farmer H, et al: Targeting the DNA repair defect in BRCA mutant cells as a therapeutic strategy. Nature 2005;434:917-921.

30 DGHO-Information für Ärzte: Patientenaufklärung vor Veranlassung einer BRCA-Mutationsanalyse zur gezielten Arzneimitteltherapie bei Ovarial- oder Mammakarzinom. www.onkopedia.com/de/wissensdatenbank/ wissensdatenbank/brcaness/brcaness (letzter Zugriff 14 . Juni 2016).
31 Huster S, Schmutzler RK: Rechtliche Aspekte aktueller Entwicklungen in der molekulargenetischen Tumordiagnostik. Medizinrecht 2015;33:248-251.

32 Plon SE, et al: Sequence variant classification and reporting: recommendations for improving the interpretation of cancer susceptibility genetic test results. Hum Mutat 2008;29:1282-1291.

33 Couch FJ, et al: Assessment of functional effects of unclassified genetic variants. Hum Mutat 2008;29:13141326.

34 Lindor NM, et al: BRCA1/2 sequence variants of uncertain significance: a primer for providers to assist in discussions and in medical management. Oncologist 2013;18:518-524.

35 Meindl A, et al: Germline mutations in breast and ovarian cancer pedigrees establish RAD51C as a human cancer susceptibility gene. Nat Genet 2010;42: 410-414.

36 Johns LE, Houlston RS: A systematic review and metaanalysis of familial colorectal cancer risk. Am J Gastroenterol. 2001;96:2992-3003.

37 Lynch HT, et al: Hereditary nonpolyposis colorectal carcinoma (HNPCC) and HNPCC-like families: problems in diagnosis, surveillance, and management. Cancer 2004;100:53-64.

38 Steinke V, et al: Erblicher Darmkrebs ohne Polyposis. Dtsch Arztebl Int 2013;110:32-38.

39 Vasen HF, et al: New clinical criteria for hereditary nonpolyposis colorectal cancer (HNPCC, Lynch syndrome) proposed by the International Collaborative group on HNPCC. Gastroenterology 1999;116:14531456.

40 Umar A, et al: Revised Bethesda Guidelines for hereditary nonpolyposis colorectal cancer (Lynch syndrome) and microsatellite instability. J Natl Cancer Inst 2004; 96:261-268.

41 Dudley JC, et al: Microsatellite instability as a biomarker for PD-1 blockade. Clin Cancer Res 2016;22 813-820.

42 Funkhouser WK Jr, et al: Relevance, pathogenesis, and testing algorithm for mismatch repair-defective colorectal carcinomas: a report of the association for molecular pathology. J Mol Diagn 2012;14:91-103.

43 Gendiagnostikgesetz vom 31. Juli 2009 (BGBl. I S. 2529, 3672), das durch Artikel 2 Absatz 31 u. Artikel 4 Absatz 18 des Gesetzes vom 7. August 2013 (BGBl. I S. 3154) geändert worden ist. 
44 Heidemann S, Schillhorn K. Gendiagnostikgesetz. Kommentar für die Praxis. Heidelberg, medhochzwei Verlag, 2011.8

45 Deutsche Gesellschaft für Hämatologie und Onkologie: Aufklärung und Einwilligungserklärung zur genetischen Untersuchung von BRCA-Mutationen am Tumorgewebe. www.onkopedia.com/de/wissensdatenbank/wissensdatenbank/brcaness/Aufklaerung\%20 und\%20Einwilligung\%20-\%20BRCA\%20Tumorgewebe\%202015.1.pdf (letzter Zugriff 14. Juni 2016).
46 Stroth M, Lüftner D: Patientenaufklärung vor BRCAMutationsanalyse. Frauenarzt 2015;56:988-995.

47 Deutscher Ethikrat: Die Zukunft der genetischen Diagnostik - von der Forschung in die klinische Anwendung. Stellungnahme. 2013. www.ethikrat.org/dateien/ pdf/stellungnahme-zukunft-der-genetischen-diagnostik. pdf (letzter Zugriff 14. Juni 2016).
48 Kitzman JO, et al: Noninvasive whole-genome sequencing of a human fetus. Sci Transl Med 2012;4: $137 \mathrm{ra76}$.

49 Ambacher N, et al: Personalisierte Medizin der Zukunft. Trendstudie des 2b AHEAD ThinkTanks, Leipzig. 2015.www.2bahead.com/studien/trendstudie/ detail/trendstudie-personalisierte-medizin (letzter Zugriff 14. Juni 2016). 